\title{
Coupling azo dye degradation and biodiesel production by manganese-dependent peroxidase producing oleaginous yeasts isolated from wood-feeding termite gut symbionts
}

\author{
Sameh Samir Ali ${ }^{1,2^{*}}$ C , Rania Al-Tohamy ${ }^{1}$, Eleni Koutra ${ }^{3,4}$, Michael Kornaros ${ }^{3,4}$, Maha Khalii ${ }^{5,2}$, Tamer Elsamahy ${ }^{1}$,
} Mohamed El-Shetehy ${ }^{2,6}$ and Jianzhong Sun ${ }^{1 *}$ (B)

\begin{abstract}
Background: Textile industry represents one prevalent activity worldwide, generating large amounts of highly contaminated and rich in azo dyes wastewater, with severe effects on natural ecosystems and public health. However, an effective and environmentally friendly treatment method has not yet been implemented, while concurrently, the increasing demand of modern societies for adequate and sustainable energy supply still remains a global challenge. Under this scope, the purpose of the present study was to isolate promising species of yeasts inhabiting wood-feeding termite guts, for combined azo dyes and textile wastewater bioremediation, along with biodiesel production.

Results: Thirty-eight yeast strains were isolated, molecularly identified and subsequently tested for desired enzymatic activity, lipid accumulation, and tolerance to lignin-derived metabolites. The most promising species were then used for construction of a novel yeast consortium, which was further evaluated for azo dyes degradation, under various culture conditions, dye levels, as well as upon the addition of heavy metals, different carbon and nitrogen sources, and lastly agro-waste as an inexpensive and environmentally friendly substrate alternative. The novel yeast consortium, NYC-1, which was constructed included the manganese-dependent peroxidase producing oleaginous strains Meyerozyma caribbica, Meyerozyma guilliermondii, Debaryomyces hansenii, and Vanrija humicola, and showed efficient azo dyes decolorization, which was further enhanced depending on the incubation conditions. Furthermore, enzymatic activity, fatty acid profile and biodiesel properties were thoroughly investigated. Lastly, a dye degradation pathway coupled to biodiesel production was proposed, including the formation of phenol-based products, instead of toxic aromatic amines.
\end{abstract}

Conclusion: In total, this study might be the first to explore the application of MnP and lipid-accumulating yeasts for coupling dye degradation and biodiesel production.

\footnotetext{
*Correspondence: samh@ujs.edu.cn; samh_samir@science.tanta.edu.eg; jzsun1002@ujs.edu.cn

${ }^{1}$ Biofuels Institute, School of the Environment and Safety Engineering, Jiangsu University, Xuefu Rd. 301, Zhenjiang 212013, China

Full list of author information is available at the end of the article
}

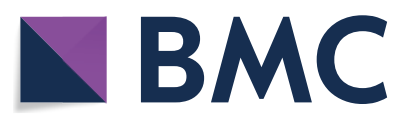

(c) The Author(s) 2021. This article is licensed under a Creative Commons Attribution 4.0 International License, which permits use, sharing, adaptation, distribution and reproduction in any medium or format, as long as you give appropriate credit to the original author(s) and the source, provide a link to the Creative Commons licence, and indicate if changes were made. The images or other third party material in this article are included in the article's Creative Commons licence, unless indicated otherwise in a credit line to the material. If material is not included in the article's Creative Commons licence and your intended use is not permitted by statutory regulation or exceeds the permitted use, you will need to obtain permission directly from the copyright holder. To view a copy of this licence, visit http://creativeco mmons.org/licenses/by/4.0/. The Creative Commons Public Domain Dedication waiver (http://creativecommons.org/publicdomain/ zero/1.0/) applies to the data made available in this article, unless otherwise stated in a credit line to the data. 
Keywords: Ligninases, Textile azo dye, Lignin degradation inhibitors, Wood-feeding termites, Oleaginous yeasts, Biodiesel

\section{Background}

Currently, most countries worldwide mainly depend on fossil fuel reserves for meeting energy requirements, which leads to various environmental, health and socioeconomic issues [1]. Furthermore, the increasing demand of modern societies for adequate energy supply results in an escalating pressure on energy production systems and natural ecosystems, which necessitate a transition in both energy production and consumption [2]. Under this scope, renewable energy sources constitute an environmentally friendly strategy towards climate change mitigation, energy security and sustainable progress, though holistic and careful assessment of renewable energy technologies should incorporate the entire range of factors, including environmental, energetic and socioeconomic ones [3]. Biofuels, mainly including bioethanol, biodiesel and biogas, have dramatically increased over the past decades and are currently represented by four generation feedstocks, each one characterized by multiple advantages and drawbacks [4]. However, biotechnological applications need further development to be fully implemented and prevail in the energy sector [5]. Besides energy crisis, the increasing industrialization, urbanization, and population which is estimated to exceed 8.5 billion by 2030, result in the production of billion tons of domestic, agricultural, and industrial wastewater.

Up to $20 \%$ of the industrial wastewater pollution emanates from textile industry, which consumes large water volumes along with chemicals during material processing, resulting in highly contaminated and colored effluents $[6,7]$. The vast use of synthetic dyes in textile industry can have detrimental effects in case the produced wastewater ends up in the environment, without prior treatment. The quantities which are annually released exceed $10^{6}$ tons [8], while due to the visible light absorbance they can severely affect microbial and plant photosynthesis [9]. Furthermore, textile wastewater affects $\mathrm{pH}$, organic carbon levels and gas solubility of aquifers [8], while mutagenic and genotoxic effects have been also described [10]. Among a wide range of available dyes, azo dyes, also used in other industries including food and paper processing and cosmetics, are the leading ones. Besides the existence of azo-groups, azo dyes are characterized by complex aromatic structure, high persistence, release of carcinogenic compounds upon degradation, as well as visible contamination even at concentrations up to $50 \mathrm{mg} / \mathrm{L}[8,11]$. The stability of azo dyes has been previously described, while up to
$87.5 \%$ could be recovered from soil after a period of two weeks, concurrently affecting the microbial community structure [12]. The available methods for textile wastewater treatment include physical, chemical, and biological processes, with the latter having significant benefits. Physical methods include adsorption, ion exchange, and filtration/coagulation, while chemical methods include ozonisation, Fenton reagent, and photocatalytic reactions $[8,13,14]$. Biological methods are based on the activity of various microorganisms, such as bacteria, yeasts, fungi and microalgae, which degrade textile wastewater and dyes through their enzymatic activity, while the combined synergistic effect of mixed microbial cultures can lead to advanced treatment $[11,15,16]$. Enzymatic degradation of textile wastewater is based on several enzymes, including laccase (Lac), lignin peroxidase (LiP), manganese peroxidase $(\mathrm{MnP})$, and azoreductase among others, while the efficiency of biodegradation depends on the concentration and adaptability of the microorganisms used, $\mathrm{O}_{2}$ levels, temperature, as well as dye and organics concentration [7, 17]. In total, biological treatment of dyeing effluents are more environmentally friendly, cost-effective, harmless to living organisms, and generate significantly lower amounts of sludge, compared to other methods [17, 18]. However, biodegradation processes are not yet applied at large scale, thus further research is needed until industrialization [7].

Up to date, the potential of yeasts for azo dyes degradation has not been fully determined, though the decolorization performance of a few species belonging to Candida, Galactomyces, and Debaryomyces genera, as well as Saccharomyces cerevisiae have been investigated [11]. A sea mud yeast isolate, determined as Pichia occidentalis was effective in Acid Red B degradation, achieving higher than $98 \%$ removal out of $50 \mathrm{mg} / \mathrm{L}$, during a 16 h-cultivation [19]. Similarly, higher than $92 \%$ removal of the Acid Scarlet GR, at a concentration of $100 \mathrm{mg} / \mathrm{L}$, was achieved by the salt-tolerant Galactomyces geotrichum yeast, while the derived metabolites were non-toxic upon plant application [20]. Furthermore, the termite isolate Sterigmatomyces halophilus could effectively metabolize up to $1.5 \mathrm{~g} / \mathrm{L}$ of the azo dye Reactive Black 5 $[13,14]$. Besides monocultures, however, as previously described in case of bacterial consortia [8], co-cultivation of microorganisms with desired characteristics can increase process effectiveness. Such enhanced performance has been observed in case of a constructed yeast consortium including three yeast isolates from termite 
guts, resulting in high bio-degradation efficiency of azo dyes, even in case of dye mixtures which could be decolorized up to about $81 \%$ [18]. Interestingly, azo dye catabolism could be combined with other valuable features of yeasts, such as lipid accumulation, to concurrently add value to the treated substrates through production of biofuels. That was the purpose of Yaguchi et al. [21] who have recently tested 36 oil-producing yeasts for their ability to degrade metabolites of lignin and additionally be utilized for lipid production. However, similar reports are rather scarce, and almost totally unexplored in case of yeast termite symbionts. Under this scope, the purpose of this study was to isolate promising species of yeasts inhabiting wood-feeding termite guts, for combined azo dyes and textile wastewater bioremediation, along with biodiesel production. For this purpose, 38 strains in total were isolated, followed by molecular identification. Yeast isolates were subsequently tested for the desired enzymatic ( $\mathrm{MnP})$ activity, lipid accumulation, and tolerance to lignin-derived metabolites. The most promising species were then used for construction of a novel yeast consortium, which was further evaluated for azo dyes degradation. Furthermore, decolorization efficiency was investigated in terms of culture conditions, azo dye levels, as well as upon the addition of heavy metals, various carbon and nitrogen sources, and lastly agro-waste as an inexpensive and environmentally friendly substrate alternative. Studies on utilization of lignin and/or ligninlike dyes by oleaginous yeasts hold much promise for achieving overall efficiency and sustainable utilization of lignocellulosic biomass and textile azo dyes for biofuel production.

\section{Results}

\section{Screening of MnP-producing yeasts isolated from termite gut symbionts}

$\mathrm{MnP}$ is an important ligninolytic enzyme responsible for the mineralization of several textile dyes of different structures, such as azo dyes, through various processes, including redox reaction, which oxidizes phenolic compounds with conversion of $\mathrm{Mn}^{2+}$ to $\mathrm{Mn}^{3+}$ [22]. Compared to filamentous fungi, dye decolorization by yeasts based on MnP production is scarce and still fragmentary $[23,24]$. Several yeast species employed for the decolorization of textile dyes through MnP production, include Candida tropicalis, Candida oleophyla, Pichia occidentalis, and Debaryomyces polymorphus [25-27]. In this study, 38 yeast isolates were positive for MnP production in terms of their clear zone formation on the YPD agar plates containing o-dianisidine dihydrochloride (a precursor of many azo dyes). These yeasts were isolated from guts of the wood-feeding termite, Reticulitermes chinenesis and Coptotermes formosanus and were mainly found to belong to the species of Candida sp., Pichia sp., Wickerhamomyces sp., Cyberlindnera sp., Candida silvanorum, Candida stauntonica, Candida tropicalis, Cyberlindnera bimundalis, Debaryomyces hansenii, Fellozyma inositophila, Meyerozyma guilliermondii, Meyerozyma caribbica, Yarrowia sp., and Vanrija humicola. However, to the best of our knowledge, there are some novel yeast species isolated from $R$. chinenesis and C. formosanus that were first to be confirmed with such feature, including Starmera dryadoides, Sterigmatomyces halophilus, Candida gotoi, and Hamamotoa lignophila. Recently, there has been an increase in the number of studies on the gut symbionts of xylophagous insects like termites, especially termite digestome, both termites and their gut symbionts, which have many potential bioenergy applications that need careful consideration [28, 29]. In contrast to previous studies on lignin breakdown, which gave no convincing evidence of microbial degradation of lignin in the termite intestinal tract [30], recent studies reported that the paunch of termites harbors a significant number of lignin-degrading yeasts [31-34]. Schäfer et al. [35] reported that yeasts were ranged between $10^{7}$ and $5 \times 10^{8}$ cells $/ \mathrm{mL}$ in the gut of Zootermopsis angusticollis and Neotermes castaneus. These yeasts were mainly represented by Candida, Pichia, and Debaromyces. On the other hand, transcriptomic analysis of termite host tissues revealed that the presence of lignin-degrading fungi in termite guts enable such symbionts for nearly complete degradation of lignocellulose [33].

After flooding the plates with $\mathrm{H}_{2} \mathrm{O}_{2}$, the reddish-brown color change was observed in around 31 yeast colonies, which is positively correlated with the production of MnP enzyme. Based on the ratio of the diameter of the clear zone to the yeast colony, 22 isolates showed a ratio higher than 5 (data not shown). In this study, nine isolates exhibited the highest extracellular MnP activity (ranged between 23 and $27 \mathrm{U} / \mathrm{mL}$ ) after $120 \mathrm{~h}$ of incubation at $25{ }^{\circ} \mathrm{C}$ in the basal medium supplemented with o-dianisidine dihydrochloride. The $\mathrm{pH}$ of the culture medium was adjusted to 5.1. These peroxidase-producing yeast isolates were identified as Cyberlindnera sp. strain SSA1583 (KX791370), Candida stauntonica SSA1653 (KY172950), Meyerozyma caribbica strain SSA1654 (KY172951), Meyerozyma guilliermondii strain SSA1547 (KX907633), Yarrowia sp. strain SSA1642 (KX907706), Candida silvanorum strain SSA1643 (KX907707), Sterigmatomyces halophilus strain SSA1655 (KY172952), Debaryomyces hansenii strain SSA1502 (KX791388), and Sugiyamaella sp. nov. strain SSA1650 (KX907714). The MnP enzyme produced by Geotrichum sp. has proved to be constitutive, achieving maximum activity within 5 days, while this yeast species showed higher MnP titers in RB5-amended medium [36]. On the other hand, $\mathrm{MnP}$ 
produced by Debaryomyces polymorphus and Candida tropicalis proved to be more inducible in a medium supplemented with dye, compared to the control [27]. Due to its broad substrate specificity, $\mathrm{MnP}$ is capable of destructing or transforming synthetic dyes into innocuous end products [37]. In addition, yeasts have potential for waste bioremediation. Therefore, screening of yeasts for ligninolytic peroxidases' activity, is of high demand since such producers have high potential for biodegradation of hazardous organic pollutants (e.g. textile azo dyes), and other biotechnological applications, such as biodiesel production.

\section{Lipid production and microbial characterization}

Twenty-two MnP-producing yeast isolates were qualitatively examined for the production of neutral lipids using Sudan black B staining. Of these yeasts, 14 isolates were stained blue and were further evaluated by Nile red staining. Sudan black B is lipophilic stain that cannot determine different lipid classes compared with Nile red, which is used to quantify intracellular neutral lipid by fluorescence spectroscopy [38]. On the other hand, seven MnP-producing yeast isolates (SR-4, SR-11, SR-18, SR-22, SR-27, SR-32 and SR-35) showed a high yellowgold coloration upon Nile red staining and fluorometric examination.

The relationship of the selected seven yeast isolates with their nearest phylogenetic relatives was also studied. These isolates proved to be closely related to the following yeast genera: Candida, Meyerozyma, Fellozyma, Vanrija, and Sterigmatomyces. The phylogenetic tree revealed that the yeast isolates SR-4, SR-11, SR-22 and SR-35 belong to Ascomycota phylum and were subsequently named as Candida stauntonica strain SSA1653 (KY172950), Meyerozyma caribbica [former Candida fermentati] strain SSA1654 (KY172951), Meyerozyma guilliermondii [former Pichia guilliermondii] strain SSA1547 (KX907633), and Debaryomyces hansenii strain SSA1502 (KX791388), respectively. The later four Ascomycetous yeast strains showed 95.40, 99.30, 100.00 and 99.49\% identity to Candida stauntonica strain ATCC MYA-4699 (JQ812698), Meyerozyma caribbica strain LZ-12 (JQ686909), Meyerozyma guilliermondii strain ML4 (MK907983), and Debaryomyces hansenii strain LL2 (EU131182), respectively (Fig. 1). The other three yeast isolates SR-18, SR-27 and SR-32 belong to Basidiomycota phylum and were denoted as Vanrija humicola [former Cryptococcus humicola] strain SSA1514 (KX791400), Sterigmatomyces halophilus strain SSA1655 (KY172952), and Fellozyma inositophila strain SSA1579 (KX791364), respectively. The later three Basidiomycetous yeast strains showed 99.34, 99.67 and $95.44 \%$ identity to Vanrija humicola strain SSA1520 (KX791406), Sterigmatomyces halophilus strain KU-79 (MG815870), and Fellozyma inositophila strain CBS 7310 (AF189987), respectively (Fig. 1).

Insects are common vectors of yeasts in nature and screening of yeasts from insect guts leads to the discovery

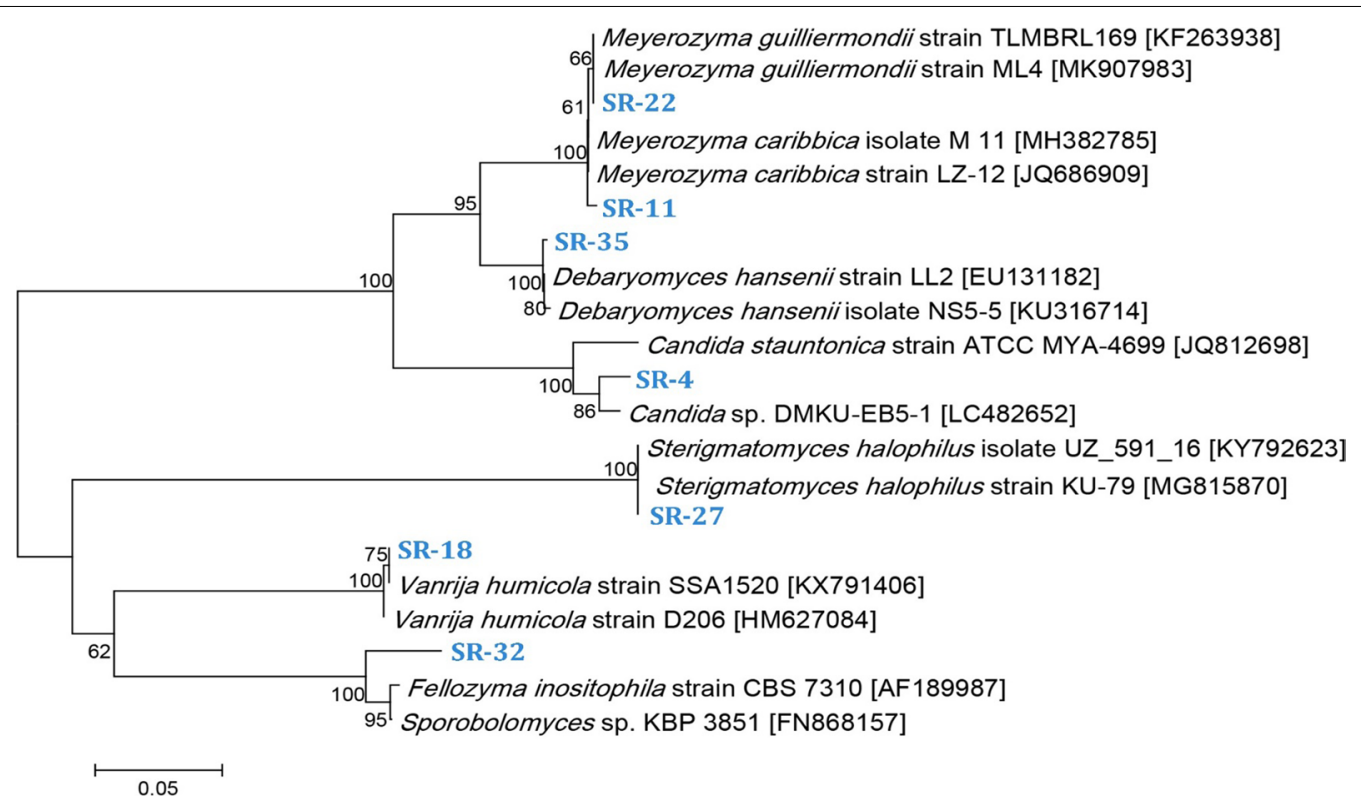

Fig. 1 A Neighbor-Joining phylogenetic tree of manganese peroxidase-producing/lipid-accumulating yeast strains with closely related taxa in NCBI database, based on the D1/D2 domain region. The horizontal bar at the bottom represents evolutionary distance as 0.05 changes per nucleotide position. Numbers next to the tree branches represent the bootstrap values as percentages of 1000 replicates 
of numerous novel yeast species with various potential biotechnological applications [13, 29, 39-41]. Termites are the most well-studied group of social insects with regard to the processing and fate of dietary carbon, while they also represent efficient lignocellulose mineralizers, capable of removing up to $99 \%$ and $87 \%$ of cellulose and hemicellulose, respectively [28]. Investigation of termites and further application of their gut-inhabiting yeasts in bioremediation and biorefinery industries is still in its infancy. To our knowledge, there have been no reports up to date on the isolation of the oleaginous yeast species Candida stauntonica from wood-feeding termites. In this study, Candida stauntonica strain SSA1653, was isolated from Coptotermes formosanus for the first time. Coptotermes formosanus is a typical lower wood-feeding termite that evolved a sophisticated lignocellulolytic system to effectively metabolize woody materials [33, 42]. Recently, Candida stauntonica was successfully isolated from the gut of adult beetle insects, which were collected from trunks and rotten wood at Henan Province, China [40]. On the other hand, the lipid-accumulating yeast strains Meyerozyma caribbica SSA1654 and Meyerozyma guilliermondii SSA1547, were successfully isolated from Coptotermes formosanus and Reticulitermes chinenesis, respectively. As reported previously, Meyerozyma caribbica and Meyerozyma guilliermondii are two closely related yeast species, belonging to the Meyerozyma guilliermondii species complex [43]. Several uses have been reported for Meyerozyma guilliermondii, including riboflavin production, enzyme production, bioconversion of xylose into xylitol, as well as biofuel production [44-46]. Besides, Meyerozyma caribbica strain DMKURK258 and Meyerozyma guilliermondii strain B1281A have been previously reported as new potential oleaginous yeasts intended for biodiesel production [47]. Moreover, yeasts of the Meyerozyma guilliermondii clade possess a wide range of anti-microbial activities against bacteria, fungi, and protozoa and can be found in insect hosts [47], opening the possibility of envisioning similar anti-microbial activity approaches.

In this study, the oleaginous yeast strain Debaryomyces hansenii SSA1502, was successfully isolated from the wood-feeding termite species Coptotermes formosanus. Ratledge and Tan [48] reported that Debaryomyces hansenii is an oil-producing yeast with high potential for the biotechnological production of both natural and artificial products. It is able to tolerate several toxins and chlorine dioxide $\left(\mathrm{ClO}_{2}\right)$, as a powerful biocide [49]. Furthermore, the ability of Debaryomyces hansenii to tolerate extreme stress could be highly advantageous in the implementation of low-cost fermentation processes [50]. It has been reported that Debaryomyces hansenii efficiently produces xylitol from D-xylose in wood hydrolysates, generating high ratios of xylitol to ethanol. Moreover, Debaryomyces hansenii synthesizes several enzymes of industrial importance, such as inulinases, esterases and $\beta$-glucosidases [50].

The lipid-accumulating Vanrija humicola (former Cryptococcus humicola) strain SSA1514 was isolated from Reticulitermes chinenesis. Souza et al. [51] reported the role of Cryptococcus humicola CCMA 0346 (isolated from soil) for lipid production. Similarly, Cryptococcus humicola strain UCDFST 10-1004 efficiently converted lignocellulosic sugars into neutral lipids (TAG) for biodiesel production [52]. Although the medical potential of several Sterigmatomyces strains has been previously reported, the newly isolated and unique yeast strain Sterigmatomyces halophilus SSA-1575, was inhabiting the gut system of Reticulitermes chinenesis and it showed great potential for dye decolorization and detoxification, as reported previously $[13,14]$. However, to the best of our knowledge, there have been no current reports on lipid accumulation belonging to this yeast species. In this study, the lipid-accumulating yeast strains Sterigmatomyces halophilus SSA1655 and Fellozyma inositophila SSA1579 were successfully isolated from Reticulitermes chinenesis.

As Nile red molecules may also non-specifically bind to specific non-lipid cellular compartments [53], lipid content quantification was necessary to confirm the yeasts' oleaginous nature. Therefore, the selected yeast strains were cultivated into the same $\mathrm{N}$-limited medium followed by lipid extraction. Biomass and lipid production were determined for the seven selected yeast strains (SSA1653, SSA1654, SSA1547, SSA1502, SSA1514, SSA1655, and SSA1579), after 5 days of incubation at $25{ }^{\circ} \mathrm{C}$ in the $\mathrm{N}$-limited glucose-based medium containing $0.5 \mathrm{~g} / \mathrm{L}$ o-dianisidine dihydrochloride as a precursor of many azo dyes. The parameters characterizing biomass and lipid production by the oleaginous yeast strains were depicted in Table 1 . The highest values of biomass $(13.28 \pm 0.57$ to $15.78 \pm 0.45 \mathrm{~g} / \mathrm{L})$, lipid production $(4.51 \pm 0.88$ to $7.10 \pm 0.85 \mathrm{~g} / \mathrm{L})$, lipid content $\left(33.96 \pm 5.72\right.$ to $47.25 \pm 1.84 \%$, w/w), $Y_{L / x}$ $(0.340 \pm 0.07$ to $0.473 \pm 0.03 \mathrm{~g} / \mathrm{g}), Y_{x / s}(0.40 \pm 0.005$ to $0.50 \pm 0.03 \mathrm{~g} / \mathrm{g}), Y_{L / s}(0.17 \pm 0.02$ to $0.23 \pm 0.01 \mathrm{~g} / \mathrm{g}), Q_{x}$ $(0.10 \pm 0.007$ to $0.15 \pm 0.004 \mathrm{~g} / \mathrm{L} / \mathrm{h})$ and $Q_{L}(0.04 \pm 0.005$ to $0.08 \pm 0.003 \mathrm{~g} / \mathrm{L} / \mathrm{h}$ ) were reached by the oleaginous yeast strains Meyerozyma caribbica SSA1654, Meyerozyma guilliermondii SSA1547, Debaryomyces hansenii SSA1502, and Vanrija humicola SSA1514 (Table 1). Our findings are in agreement with those reported by Maza et al. [54] who found that Rhodotorula glutinis R4, Rhodotorula toruloides Y-1091, Rhodotorula toruloides Y-6987, and Rhodotorula toruloides Y-6985 revealed the highest values of biomass (14-16 g/L), lipid production 
Table 1 Biomass and lipid parameters produced by the oleaginous MnP-producing yeast strains isolated from termite gut symbionts

\begin{tabular}{|c|c|c|c|c|c|c|c|c|}
\hline Yeast strains* & $\begin{array}{l}\text { Biomass } \\
(\mathrm{g} / \mathrm{L})\end{array}$ & $\begin{array}{l}\text { Lipid } \\
\text { (g/L) }\end{array}$ & $\begin{array}{l}\text { Lipid content } \\
(\%, w / w)\end{array}$ & $\begin{array}{l}Y_{L / x} \\
(g / g)\end{array}$ & $\begin{array}{l}Y_{x / s} \\
(\mathbf{g} / g)\end{array}$ & $\begin{array}{l}Y_{L / s} \\
(g / g)\end{array}$ & $\begin{array}{l}Q_{x} \\
(g / L / h)\end{array}$ & $\begin{array}{l}Q_{L} \\
(\mathrm{~g} / \mathrm{L} / \mathrm{h})\end{array}$ \\
\hline $\begin{array}{l}\text { Meyerozyma caribbica } \\
\text { SSA1654 }\end{array}$ & $14.71 \pm 0.38^{\mathrm{a}}$ & $6.95 \pm 1.77^{\mathrm{a}}$ & $47.25 \pm 1.84^{\mathrm{a}}$ & $0.473 \pm 0.03^{\mathrm{a}}$ & $0.50 \pm 0.03^{a, c}$ & $0.22 \pm 0.03^{\mathrm{a}}$ & $0.14 \pm 0.004^{\mathrm{a}}$ & $0.08 \pm 0.003^{\mathrm{a} . \mathrm{c}}$ \\
\hline $\begin{array}{l}\text { Vanrija humicola } \\
\text { SSA1514 }\end{array}$ & $15.23 \pm 0.09^{a, b}$ & $6.62 \pm 1.13^{\mathrm{a}}$ & $43.46 \pm 5.34^{a, b}$ & $0.435 \pm 0.08^{\mathrm{a}}$ & $0.47 \pm 0.008^{\mathrm{a}}$ & $0.23 \pm 0.04^{a}$ & $0.15 \pm 0.009^{\mathrm{a}}$ & $0.05 \pm 0.007$ \\
\hline $\begin{array}{l}\text { Meyerozyma guillier- } \\
\text { mondii SSA } 1547\end{array}$ & $15.78 \pm 0.45^{a, b}$ & $7.10 \pm 0.85^{a, c}$ & $44.74 \pm 6.09^{a, b}$ & $0.447 \pm 0.07^{\mathrm{a}}$ & $0.48 \pm 0.009^{a}$ & $0.23 \pm 0.01^{\mathrm{a}}$ & $0.15 \pm 0.004^{\mathrm{a}}$ & $0.06 \pm 0.005^{a}$ \\
\hline $\begin{array}{l}\text { Debaryomyces hanse- } \\
\text { nii SSA1502 }\end{array}$ & $13.28 \pm 0.57$ & $4.51 \pm 0.88$ & $33.96 \pm 5.72$ & $0.340 \pm 0.07$ & $0.40 \pm 0.005$ & $0.17 \pm 0.02$ & $0.10 \pm 0.007$ & $0.04 \pm 0.005$ \\
\hline
\end{tabular}

The values are mean of three independent experiments. Values followed by the same letters showed insignificant difference; *Yeasts were grown in the $\mathrm{N}$-limited

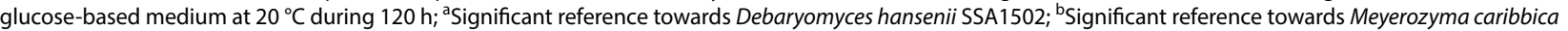
SSA1654; 'Significant reference towards Vanrija humicola SSA1514

(6.8-7.3 g/L), lipid content (43.9-48.9\%, w/w), $Y_{L / x}(0.45-$ $0.50 \mathrm{~g} / \mathrm{g}), Y_{x / s}(0.40-0.47 \mathrm{~g} / \mathrm{g}), Y_{L / s}(0.18-0.22 \mathrm{~g} / \mathrm{g}), Q_{x}$ $(0.119-0.134 \mathrm{~g} / \mathrm{L} / \mathrm{h})$ and $Q_{L}(0.057-0.061 \mathrm{~g} / \mathrm{L} / \mathrm{h})$. On the other hand, Candida viswanathii Y-E4 showed the highest lipid yield (3.55 g/L). However, Rhodotorula babjevae Y-SL7 showed the highest lipid content (39.2\%) and lipid yield by consumed glucose $\left(\mathrm{Y}_{\mathrm{L} / \mathrm{s}}, 0.1 \mathrm{~g} / \mathrm{g}\right)$ as reported by Ayadi et al. [55]. As depicted in Table 2, various other oleaginous yeast genera, such as Cryptococcus, Cyberlindera, Candida, Cystobasidium, Rhodotorula, Rhodosporidium, and Yarrowia, have been reported to have comparable values of biomass, lipid content and lipid productivity

Table 2 Lipid production by different oleaginous yeasts reported in literature

\begin{tabular}{|c|c|c|c|c|c|c|c|}
\hline Oleaginous yeast & Source & Carbon source & Cultivation mode & $\begin{array}{l}\text { Biomass } \\
\text { production } \\
\text { (g/L) }\end{array}$ & $\begin{array}{l}\text { Lipid } \\
\text { content } \\
(\%)\end{array}$ & $\begin{array}{l}\text { Lipid } \\
\text { productivity } \\
\text { (g/L/h) }\end{array}$ & Reference \\
\hline $\begin{array}{l}\text { Rhodotorula toruloides } \\
\text { Y-1091 }\end{array}$ & Culture collection & Glucose & Batch & 14.90 & 48.93 & 0.06 & Maza et al. [54] \\
\hline $\begin{array}{l}\text { Rhodotorula glutinis } \\
\text { R4 }\end{array}$ & Soil & Glucose & Batch & 14.325 & 47.24 & 0.057 & Maza et al. [54] \\
\hline $\begin{array}{l}\text { Candida viswanathii } \\
\text { Y-E4 }\end{array}$ & Soil & Glucose & Batch & 13.62 & 25.33 & 0.029 & Ayadi et al. [56] \\
\hline $\begin{array}{l}\text { Cystobasidium oli- } \\
\text { gophagum JRC1 }\end{array}$ & Soil & Glucose & Batch & 12.34 & 39.44 & 0.029 & Vyas and Chhabra [57] \\
\hline $\begin{array}{l}\text { Rhodosporidium kra- } \\
\text { tochvilovae HIMPA1 }\end{array}$ & Soil & Glucose & Batch & 14.46 & 41.92 & 0.037 & Patel et al. [58] \\
\hline $\begin{array}{l}\text { Cyberlindera fabianii } \\
\text { Y-B14 }\end{array}$ & Olive pomace & Glucose & Batch & 6.01 & 25.58 & ND & Ayadi et al. [55] \\
\hline Candida tropicalis Y-L2 & Palm juice & Glucose & Batch & 6.23 & 22.10 & ND & Ayadi et al. [55] \\
\hline $\begin{array}{l}\text { Yarrowia lipolytica } \\
\text { Y-RC7 }\end{array}$ & Cheese wastewater & Glucose & Batch & 6.81 & 26.63 & ND & Ayadi et al. [55] \\
\hline Cryptococcus curvatus & Culture collection & Sorghum bagasse & Batch & 6.0 & NA & 0.036 & Liang et al. [59] \\
\hline $\begin{array}{l}\text { Rhodosporidium } \\
\text { toruloides Y4 }\end{array}$ & NA & Corn stover & Batch & 14.2 & 51.8 & 0.035 & Xie et al. [60] \\
\hline $\begin{array}{l}\text { Meyerozyma caribbica } \\
\text { SSA1654 }\end{array}$ & Termite gut & Glucose & Batch & 14.71 & 47.25 & 0.08 & This study \\
\hline $\begin{array}{c}\text { Meyerozyma guillier- } \\
\text { mondii SSA1547 }\end{array}$ & Termite gut & Glucose & Batch & 15.78 & 44.74 & 0.06 & This study \\
\hline $\begin{array}{l}\text { Vanrija humicola } \\
\text { SSA1514 }\end{array}$ & Termite gut & Glucose & Batch & 15.23 & 43.46 & 0.05 & This study \\
\hline $\begin{array}{l}\text { Debaryomyces hanse- } \\
\text { nii SSA1502 }\end{array}$ & Termite gut & Glucose & Batch & 13.28 & 33.96 & 0.04 & This study \\
\hline
\end{tabular}

NA not available, $N D$ not determined 
in case of glucose or biomass waste used as a carbon source. Meyerozyma caribbica SSA1654, isolated from termite gut symbionts, showed higher lipid productivity and comparable with Rhodotorula toruloides Y-1091 [54], Rhodotorula glutinis R4 [54], Candida viswanathii Y-E4A [56], Cystobasidium oligophagum JRC1 [57], Rhodosporidium kratochvilovae HIMPA1 [58], Cryptococcus curvatus [59], and Rhodosporidium toruloides Y4 [60].

To produce biodiesel, selection of yeasts with oleaginous nature is a vital stage, followed by the implementation of the appropriate cultivation system for growth and lipid accumulation. The produced biomass was harvested, proceeding with the extraction of lipids from oleaginous yeasts, followed by the transesterification into fatty acid methyl esters (FAMEs) [61]. In that context, four strains (Meyerozyma caribbica SSA1654, Meyerozyma guilliermondii SSA1547, Debaryomyces hansenii SSA1502, and Vanrija humicola SSA1514) appeared as promising oleaginous yeasts, with accumulated lipids between $33.96 \pm 5.72$ and $47.25 \pm 1.84 \%(\mathrm{w} / \mathrm{w})$ (Table 1 ), when compared with the commercial oleaginous yeast strain Yarrowia lipolytica W29 which produces $1.7 \mathrm{~g} / \mathrm{L}$ corresponding to $29 \%$ of lipid content [55]. Ascomycetes, such as Candida tropicalis and Yarrowia lipol$y$ tica, are the best lipid-producing yeasts [62]. In this study, the highest percentage of lipid accumulation was recorded for the first time for Meyerozyma caribbica strain SSA1654, isolated from wood-feeding termite guts, since it showed a remarkable ability of lipid accumulation up to $47.25 \pm 1.84 \%$ (w/w). Maza et al. [54] reported that among nine oleaginous yeast strains evaluated for lipid production, Rhodotorula glutinis R4 showed the highest lipid production $(7 \mathrm{~g} / \mathrm{L} ; 47 \% \mathrm{w} / \mathrm{w})$ with efficient growth and glucose consumption. The highest lipid yield (39.2\%) was achieved by Rhodotorula babjevae Y-SL7, while the highest lipid content $(3.55 \mathrm{~g} / \mathrm{L})$ was achieved by Candida viswanathii Y-E4, since xylose was used as the carbon source [55].

\section{Yeast growth, glucose residual and nitrogen assimilation with respect to lipid production}

The oleaginous yeast strains (Meyerozyma caribbica SSA1654, Meyerozyma guilliermondii SSA1547, Debaryomyces hansenii SSA1502, and Vanrija humicola SSA1514) were grown in liquid N-limited glucose-based medium supplemented with o-dianisidine dihydrochloride. The inoculated flasks were incubated at $25{ }^{\circ} \mathrm{C}$; meanwhile, all yeasts were characterized using the classic growth curves for $120 \mathrm{~h}$. Clearly, the oleaginous yeast strains presented the typical growth curves with logarithmic and stationary phases (Fig. 2). The cells entered stationary phase and thus no substantial OD increase was observed after the depletion of nitrogen. However, glucose consumption continued until the end of experiments at $120 \mathrm{~h}$. Nitrogen was almost completely depleted after 24 h of growth, with assimilation reaching up to $96 \%$, while residual glucose was less than 15\% inducing the onset of stationary growth phase. At the end of the incubation time $(120 \mathrm{~h}), 3.9-5.2 \%$ of glucose remained in the cultures of the oleaginous yeast strains SSA1654, SSA1547, SSA1502, and SSA1514, respectively (Fig. 2).

On the other hand, nitrogen was sharply depleted within $24 \mathrm{~h}$, achieving $86-96.4 \%$ removal, and then remained constant for all yeast strains until the end of the incubation time (Fig. 2). In the presence of excess carbon source, yeasts accumulate it in the form of TAG, comparing with bacteria that metabolize carbon into polysaccharides and polyhydroxyalkanoates [61]. Such yeasts can produce lipids by metabolizing different carbon sources [63]. As previously reported, oleaginous yeasts can accumulate lipids which are similar to vegetable oils [64].

Among the four oleaginous yeast strains, Meyerozyma caribbica SSA1654 reached the highest lipid production $(47.25 \pm 1.84 \%, \mathrm{w} / \mathrm{w})$ with an initial nitrogen assimilation of $137.5 \mathrm{mg} / \mathrm{L}$ and $40 \mathrm{~g} / \mathrm{L}$ of glucose (Fig. 2c), resulting in a glucose-rich culture medium, though poor in nitrogen. As a result of such an unbalanced metabolism, the oleaginous yeasts can continue glucose uptake, which is further converted into TAG and stored as energy reserves. Evans and Ratledge [65] reported three growth phases of oleaginous yeasts under nutrient limitation conditions. Of those, exponential phase exhibits rapid proliferation of yeast cells. In the lipid accumulation phase, yeast cells show minimum growth due to nutrient limitation (e.g. nitrogen, sulfur and phosphorus), while in the stationary phase, catabolic breakdown of lipid occurs resulting in low lipid content. However, upon the depletion of nitrogen, the intracellular concentration of $\mathrm{NH}_{4}{ }^{+}$was rapidly increased by oleaginous yeasts since the adenine-monophosphate (AMP) was broken down by AMP-deaminase to give inosine-mono-phosphate (IMP) and $\mathrm{NH}_{4}{ }^{+}$(as a temporary nitrogen source for the yeasts to continue their growth) [66]. Furthermore, Meyerozyma caribbica SSA1654 is a cold-tolerant oleaginous yeast and it has been reported that cold-tolerant or cold-adapted yeasts are excellent candidates for microbial lipids production [67]. These yeasts have a high content of mono-unsaturated fatty acid (MUFA), mainly oleic acid (C18:1), and are potentially valuable for biodiesel production under cold conditions, e.g. during the winter period [68].

\section{Characterization of extracted lipids}

Fatty acid composition of microbial lipids, determined as FAME profile, greatly affects biodiesel properties. Under this scope, TAG synthesized by Meyerozyma caribbica 

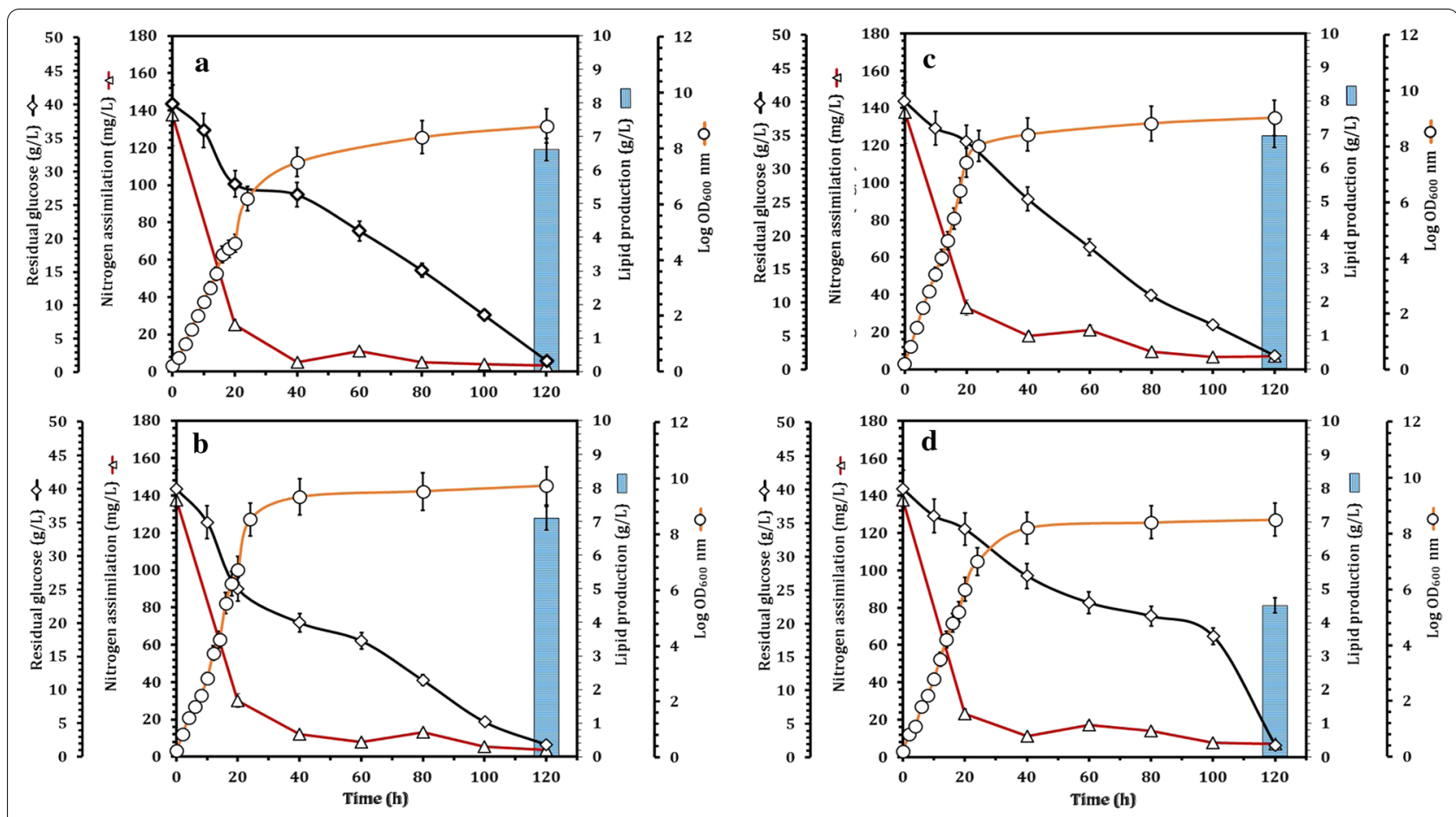

Fig. 2 Oleaginous yeast strains; V. humicola SSA1514 (a), M. guilliermondii SSA1547 (b), M. caribbica SSA1654 (c), and D. hansenii SSA1502 (d) showing their growth $\left(\log \mathrm{OD}_{600} \mathrm{~nm}\right)$, residual glucose, nitrogen assimilation in association with lipid production, after 5 days of cultivation in $\mathrm{N}$-limited glucose-based medium. Values are mean of three independent replicates and the standard deviation is indicated by error bars

SSA1654 was assessed. Table 3 depicts the fatty acid composition of Meyerozyma caribbica SSA1654, which was mainly rich in long-chain fatty acids (C16 and C18), compared to olive oil. The saturated fatty acid (SFA), MUFA and poly-unsaturated fatty acid (PUFA) represent over $95 \%$ of total fatty acids, which are similar to that of vegetable oils, containing predominantly SFA or MUFA with 16 and 18 carbon atoms [54, 55, 69], suggesting that Meyerozyma caribbica SSA1654 represents a potential candidate for third-generation biodiesel production. The FAME profile of Meyerozyma caribbica SSA1654 revealed that fatty acids with $\mathrm{C} 18$ were the most abundant, representing 76.22\% (Table 3). Rossi et al. [67] reported that fatty acids with $\mathrm{C} 18$ chain length appear as an adaptive character of oleaginous yeasts which are grown under cold conditions. Such habitats may be necessary for the elongation of fatty acids beyond C16 by introducing additional double bonds via $\Delta 12$ and $\Delta 15$ denaturases [67]. On the other hand, the content of oleic acid (C18:1) in Meyerozyma caribbica SSA1654 was found to be $60.73 \%$, while palmitic acid (C16:0) and linoleic acid (C18:2) contents were $17.34 \%$ and $9.56 \%$ of the total fatty acids, respectively (Table 3 ). The fatty acid composition of Meyerozyma caribbica SSA1654 is in accordance with that of other oleaginous yeast previously reported [15, 54]. Total UFA of Meyerozyma caribbica
Table 3 Fatty acid profile produced by oleaginous yeast strain SSA16541, comparing with common vegetable oil

\begin{tabular}{|c|c|c|}
\hline & \multicolumn{2}{|c|}{ Relative fatty acid content $(\%, \mathrm{w} / \mathrm{w})$} \\
\hline & $\begin{array}{l}\text { Meyerozyma } \\
\text { caribbica strain } \\
\text { SSA1654 }\end{array}$ & Olive oil \\
\hline Myristic acid (C14:0) & 1.78 & 0.0 \\
\hline Pentadecanoic acid (C15:0) & 0.59 & Not determined \\
\hline Palmitic acid (C16:0) & 17.34 & 11.6 \\
\hline Palmitoleic acid (C16:1) & 1.60 & 1.0 \\
\hline Stearic acid (C18:0) & 1.86 & 3.1 \\
\hline Oleic acid (C18:1) & 60.73 & 75.0 \\
\hline Linoleic acid (C18:2) & 9.56 & 7.8 \\
\hline Linolenic acid (C18:3) & 4.07 & 0.1 \\
\hline Total C16 & 18.94 & 12.6 \\
\hline Total C18 & 76.22 & 86.0 \\
\hline Total saturated fatty acid & 19.2 & 14.7 \\
\hline $\begin{array}{l}\text { Total mono-unsaturated fatty } \\
\text { acid }\end{array}$ & 62.33 & 76.0 \\
\hline Total poly-unsaturated fatty acid & 13.63 & 7.9 \\
\hline Reference & This study & Ramos et al. [69] \\
\hline
\end{tabular}

Meyerozyma caribbica SSA1654 was grown in the $\mathrm{N}$-limited medium supplemented with $40 \mathrm{~g} / \mathrm{L}$ of glucose at $20^{\circ} \mathrm{C}$ during $120 \mathrm{~h}$; The values are mean of three independent experiments 
SSA1654 were predominant (75.96\%), while total SFA, represented $19.2 \%$ (Table 3), in agreement with previous results [54]. In total, the ratio of UFA and SFA of the produced FAME is critical for evaluating biodiesel quality [69], therefore, Meyerozyma caribbica SSA1654 is propitious for biodiesel synthesis.

\section{Assessment of biodiesel quality produced by Meyerozyma caribbica SSA 1654}

The main physicochemical properties of biodiesel produced by Meyerozyma caribbica SSA1654, including cetane number $(\mathrm{CN})$, iodine value (IV), saponification value (SV), kinematic viscosity $(v)$, density $(\rho)$, oxidative stability (OS), long-chain saturation factor (LCSF), and degree of unsaturation (DU) were estimated (Table 4). The obtained values were compared with those produced from olive oil [69], and the international biodiesel standard EN 14214 [70]. It has been reported that the ratio of UFA and SFA must be optimum to enhance biodiesel quality [69]. In this study, the $\mathrm{CN}$ of the biodiesel produced by Meyerozyma caribbica SSA1654 was found to be 52.32 . This value met the $\mathrm{CN}$ values of EN 14214 $(\mathrm{CN} \geq 51)$. Patel et al. [61] reported that high $\mathrm{CN}$ value ensures less pollutant emissions and better combustion, accordingly, producing efficient engine performance. The IV value of the biodiesel produced by Meyerozyma caribbica SSA1654 was $92.37 \mathrm{~g} \mathrm{I}_{2} / 100 \mathrm{~g}$ and it met the value established by EN 14214 (Table 4). As reported previously [71], IV value is greatly affected by the UFA degree and it ensures the oxidation stability of the fuel. The quality of biodiesel also depends on the $v$ and $\rho$ values. As shown in Table 4, the $v$ value of biodiesel produced by Meyerozyma caribbica SSA1654 $\left(3.98 \mathrm{~mm}^{2} / \mathrm{s}\right)$ met that estimated from the standard biodiesel EN 14214, which ranged between 3.5 and $5.0 \mathrm{~mm}^{2} / \mathrm{s}$. Maza et al. [54] reported that the appropriate $v$ value ensures adequate biodiesel supply at various operating temperatures. Also, the $\rho$ value of the biodiesel produced by Meyerozyma caribbica SSA1654 was found to be $0.88 \mathrm{~g} / \mathrm{cm}^{3}$ and it met the $\rho$ value established by EN 14214 (Table 4). The $\rho$ value of a biodiesel determines its net energy content [61]. The SV, OS, LCSF and DU values of the biodiesel produced by Meyerozyma caribbica SSA1654 were $199.4 \mathrm{mg} \mathrm{KOH}, 8.30 \mathrm{~h}, 3.34 \%$ wt., and $96.85 \%$ wt., respectively. These results are in accordance with previous findings [54,61]. The biodiesel produced by Meyerozyma caribbica SSA1654 showed a C18:3 content of $5.72 \%$, which met the content of biodiesel established by EN $14214(\leq 12)$. Therefore, the results demonstrated the potential of the MnP-producing/TAG-accumulating Meyerozyma caribbica SSA1654 as a novel candidate for biodiesel production.

\section{Enzyme activity}

The activities of $\beta$-glucosidase, CMCase, xylanase and lipase produced by Meyerozyma caribbica SSA1654, were determined. The time course of $\beta$-glucosidase revealed that all yeast strains achieved the maximum production after three days of incubation with the highest activity of $0.38 \pm 0.06 \mathrm{U} / \mathrm{mg}$ by Meyerozyma caribbica SSA1654. The activities of CMCase and xylanase initiated the first day of cultivation and reached their maximum production after three and four days, respectively. CMCase and xylanase reached their maximum activities of $0.17 \pm 0.03$ and $5.8 \pm 0.9 \mathrm{U} / \mathrm{mg}$ by Meyerozyma caribbica SSA1654, respectively. The activities of $\beta$-glucosidase, CMCase, and xylanase of the given MnP-producing oleaginous yeast strains were comparable with the recently reported oleaginous yeasts. The oleaginous yeast strain Trichosporon asahii Y-SL1 reached the maximum CMCase $(0.11$ $\mathrm{U} / \mathrm{mL})$ and $\beta$-glucosidase $(0.55 \mathrm{U} / \mathrm{mL})$ after three and four days of culture [55]. Pseudozyma brasiliensis showed the highest $\beta$-glucosidase of $0.14 \mathrm{IU} / \mathrm{mL}$ [72]. Cystobasidium oligophagum JRC1 exhibited the highest specific enzyme activity for $\beta$-glucosidase $(0.98 \pm 0.04 \mathrm{IU} /$

Table 4 Biodiesel properties produced by Meyerozyma caribbica SSA1654 in comparison with those of olive oil and the international biodiesel standard EN 14214

\begin{tabular}{llll}
\hline Biodiesel properties & Meyerozyma caribbica SSA1654 & Olive oil & EN 14214 \\
\hline Long chain saturated factor $(\%, \mathrm{wt})$ & 3.34 & 4.2 & Not specified \\
Kinematic viscosity $\left(\mathrm{mm}^{2} / \mathrm{s}\right)$ & 3.98 & 4.5 & $3.5-5.0$ \\
lodine value $\left(\mathrm{g} \mathrm{I}_{2} / 100 \mathrm{~g}\right)$ & 92.37 & 84.0 & $\leq 120$ \\
Cetane number & 52.32 & 57.0 & Not determined \\
Saponification value $(\mathrm{mg} \mathrm{KOH})$ & 199.4 & 0.6 & Not specified \\
Linolenic acid $(\mathrm{C} 18: 3)$ & 4.07 & 92.7 & $\leq 12$ \\
Degree of unsaturation $(\%, \mathrm{wt})$ & 95.85 & Not specified & Not specified \\
Density $\left(\mathrm{g} / \mathrm{cm}^{3}\right)$ & 0.88 & 3.3 & $0.86-0.9$ \\
Oxidation stability $(\mathrm{h})$ & 8.3 & Ramos et al. [69] & $\geq 6$ \\
Reference & This study & & CEN [70] \\
\hline
\end{tabular}


$\mathrm{mg})$ and CMCase $(2.27 \pm 0.007 \mathrm{IU} / \mathrm{mg})$ with enzymatic activities of $0.03 \pm 0.01$ and $0.072 \pm 0.01 \mathrm{IU} / \mathrm{mL}$, respectively [57]. On the other hand, the production rate of lipase activity revealed $55.3 \pm 5.4 \mathrm{U} / \mathrm{mL}$ for Meyerozyma caribbica SSA1654. The production rate of lipase activity varied from $16.6 \mathrm{U} / \mathrm{mL}$ for Candida viswanathii Y-E4 to $50 \mathrm{U} / \mathrm{mL}$ for Yarrowia lipolytica Y-D1P [56]. Cystobasidium oligophagum JRC1 revealed the highest lipase activity of $0.14 \pm 0.009 \mathrm{IU} / \mathrm{mL}$ and specific activity of $2.88 \pm 0.17 \mathrm{IU} / \mathrm{mg}$ after $84 \mathrm{~h}$ of incubation [57]. Several oleaginous yeast species, such as Lipomyces starkeyi and Yarrowia lipolytica, have been reported to produce lipase and their utilization as a catalyst for biodiesel (FAME) production has also been reported [73]. However, in the present study, the oleaginous yeast species Meyerozyma caribbica, isolated from wood-feeding termite symbionts, was identified for the first time as a cellulase, xylanase and lipase producer, suggesting that the MnP-producing oleaginous yeasts Meyerozyma caribbica could be potential candidate for valorizing lignocellulosic/fatty wastes into high added-value products.

\section{Tolerance to lignin degradation inhibitors}

Lignin is a heterogeneous biopolymer mainly consisting of syringyl, guaiacyl and hydroxyphenyl units [74]. Various microorganisms can bio-transform lignin and lignocellulose feedstocks into lipids, the raw material for biodiesel production [75-77]. However, various inhibitory compounds are generated, including weak acids (acetic acid, levulinic acid, and formic acid) and furans (furfural and 5-hydroxymethylfurfural), and phenolic compounds (syringaldehyde, 4-hydroxybenzaldehyde, and vanillin) [78-80]. The tolerance to lignin degradation inhibitors is considered as highly technical challenge for lipid production [81]. Therefore, screening of oleaginous yeasts using lignin or lignocellulose feedstocks is of great importance to accumulate high lipid content simultaneously with tolerance to various inhibitors. Oleaginous yeasts have been previously reported for their high tolerance to lignocellulosic degradation inhibitors [82-84]. This study provides the first insight into the tolerance of peroxidase-producing oleaginous yeast strains isolated from termite gut symbionts to various inhibitors for lipid production for future industrial applications. The tolerance comparison of the four MnP-producing oleaginous yeast strains Meyerozyma caribbica SSA1654, Meyerozyma guilliermondii SSA1547, Debaryomyces hansenii SSA1502, and Vanrija humicola SSA1514 to six inhibitory compounds (furfural, 5-hydroxymethylfurfural, vanillin, 4-hydroxybenzaldehyde, syringaldehyde, and levulinic acid) was evaluated. Between those oleaginous yeasts, Meyerozyma caribbica SSA1654 showed a high surviving potential in the presence of high lignin degradation inhibitors, while Vanrija humicola SSA1514 showed the lowest tolerance (data not shown). The performance of Meyerozyma caribbica SSA1654 to tolerate lignin inhibitors as well as to accumulate lipids is presented in Fig. 3.

Compared to the control, the dry cell weight (DCW) and lipid content of Meyerozyma caribbica SSA1654 were significantly decreased, since at a concentration of $0.5 \mathrm{~g} / \mathrm{L}$, furfural reduced the DCW and lipid content by 55.4 and $66.7 \%$, respectively (Fig. 3a). However, the other furan inhibitor (5-hydroxymethylfurfural) showed less toxicity on Meyerozyma caribbica SSA1654 compared to furfural, in which DCW and lipid content were insignificantly decreased with increasing the concentration of 5-hydroxymethylfurfural, resulting in reduction of 13.3\% (DCW) and $47.5 \%$ (lipid content) in the presence of $2.5 \mathrm{~g} / \mathrm{L}$ of 5-hydroxymethylfurfural (Fig. 3b). It has been reported that furfural and 5-hydroxymethylfurfural are reduced to furfuryl alcohol and 5-hydroxymethylfurfural alcohol, respectively, and then oxidized back to furfural and 5-hydroxymethylfurfural but at very low concentrations, which are not harmful to the oleaginous yeast growth [80].

On the other hand, the performance of Meyerozyma caribbica SSA1654 to tolerate the three typical phenolic aldehydes, namely syringaldehyde, vanillin and 4-hydroxybenzaldehyde, was studied to represent the lignin derivatives of syringyl group (S), guaiacyl group (G) and hydroxyphenyl group $(\mathrm{H})$, respectively (Fig. 3c-e). Syringaldehyde showed no significant difference with negligible inhibition on the DCW and lipid content of Meyerozyma caribbica SSA1654, up to a concentration of $2.5 \mathrm{~g} / \mathrm{L}$ (Fig. 3c), while vanillin showed partial inhibition of the yeast growth and lipid content up to the concentration of $2.5 \mathrm{~g} / \mathrm{L}$ (Fig. 3d). However, 4-hydroxybenzaldehyde significantly inhibited the DCW at $2.0 \mathrm{~g} / \mathrm{L}$, while both DCW and lipid content were almost completely inhibited at $2.5 \mathrm{~g} / \mathrm{L}$ of 4-hydroxybenzaldehyde (Fig. 3e). Similar to furfural and 5-hydroxymethylfurfural, the three typical phenolic aldehydes (syringaldehyde, vanillin and 4-hydroxybenzaldehyde) are converted into their corresponding alcohols, then the acids are finally converted into acetyl-CoA before being assimilated into the tricarboxylic acid (TCA) cycle [80]. On the other hand, levulinic acid led to a significant reduction in the DCW and lipid content of Meyerozyma caribbica SSA1654 with increasing the concentration of levulinic acid up to $25 \mathrm{~g} / \mathrm{L}$ (Fig. 3f). Weak acid inhibitors are converted into acetyl-CoA, then ultimately enter the TCA cycle [80]. Clearly, the robustness of Meyerozyma caribbica SSA1654 could be demonstrated by comparing it with other oleaginous yeast strains under the stress of lignin 


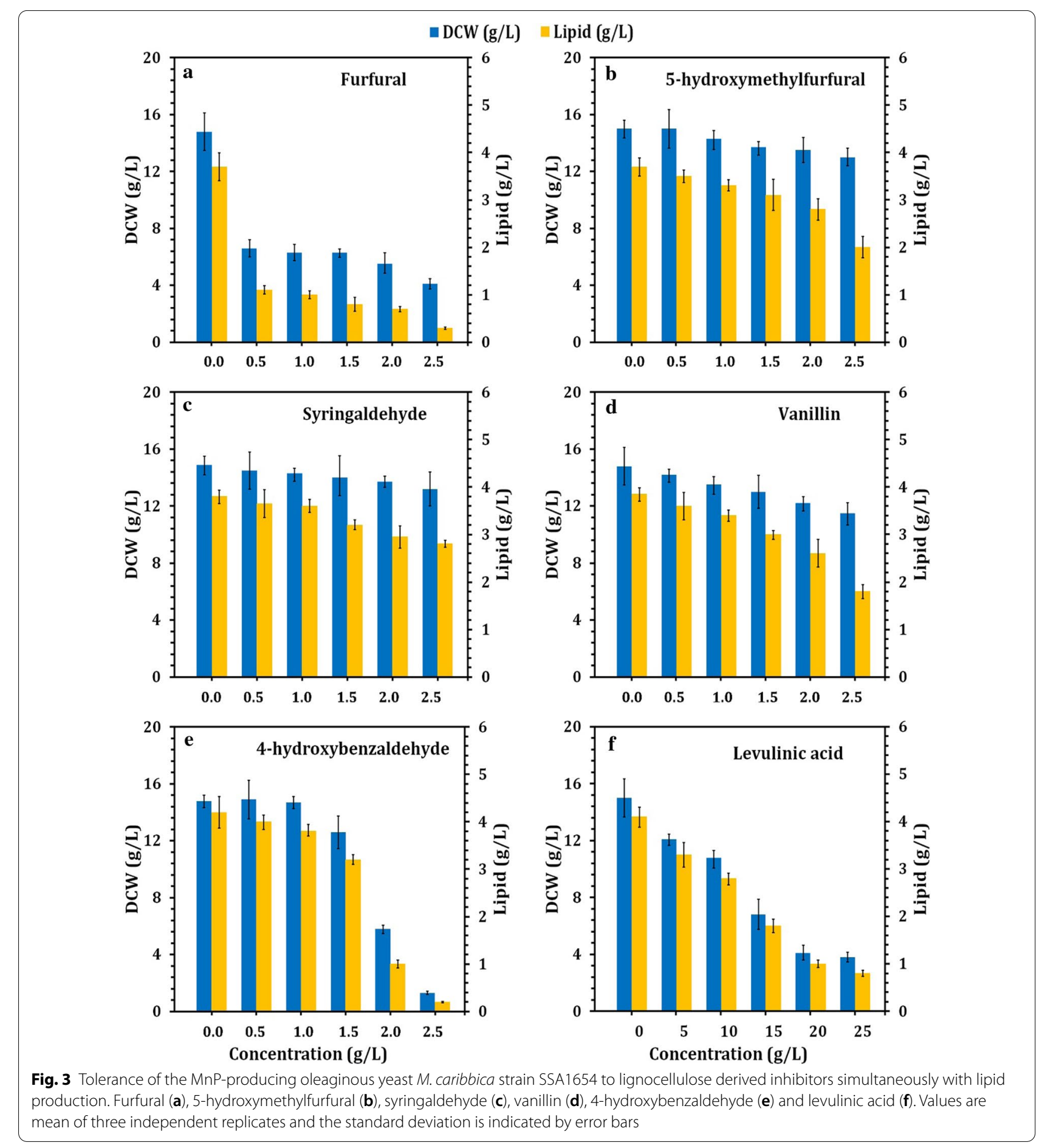

degradation inhibitors. Vanillin $(2 \mathrm{~g} / \mathrm{L})$ and 4-hydroxybenzaldehyde $(1.2 \mathrm{~g} / \mathrm{L})$ led to complete inhibition of Rhodosporidium toruloides Y4 and Rhodosporidium toruloides AS2.1389, while syringaldehyde partially inhibited the growth of both yeast strains (decreased by $15.7 \%)$ at a concentration of $2.19 \mathrm{~g} / \mathrm{L}[85,86]$. 
Performance of oleaginous yeast consortium NYC-1 for dye decolorization

Bioremediation of textile wastewater as a cheap source for water containing organic dyes (a potential carbon source) and successive biodiesel production can fulfill the energy requirements of textile dye industry $[15,87,88]$. Besides, biological conversion could serve as a potential platform for upgrading lignin or lignin-like dyes. In this scenario, application of microbial consortia and their enzymatic system is of great importance for utilizing various aromatics [76]. Therefore, a new oleaginous yeast consortium NYC-1 which stands for the molecularly identified yeast strains Meyerozyma caribbica SSA1654, Meyerozyma guilliermondii SSA1547, Debaryomyces hansenii SSA1502, and Vanrija humicola SSA1514 was successfully constructed in this study. As far as we know, many strains of guilliermondii, humicola and hansenii play an important role in degradation of azo dyes, such as Meyerozyma guilliermondii Y011, Vanrija humicola D206, and Debaryomyces hansenii F39A [15, 89, 90]. However, none of the previous studies has reported the biodegradation of textile azo dyes using constructed oleaginous microbial consortia. Interestingly, Meyerozyma caribbica has not been previously described in the literature to decolorize azo dyes. Therefore, the performance of the MnP-producing oleaginous yeast consortium NYC-1 to decolorize various industrial azo dyes viz. 10 azo dyes, i.e. Acid Orange 7 (AO7), Reactive Green 19 (RG19), Scarlet GR (SGR), Reactive Black 5 (RB5), Methyl Orange (MO), Reactive Blue 19 (RB19), Reactive Blue 81 (RB81), Methyl Red (MR), Reactive Red 120 (RR120), and Reactive Violet 5 (RV5) was studied and the results are depicted in Additional file 1: Table S1. The average decolorization rate of such azo dyes for the NYC-1 consortium was significantly higher than that observed for its pure cultures (data not shown). Enhanced rate of dye decolorization using bacterial and/or yeast consortia has been reported earlier $[15,18,91,92]$. On the other hand, it has been observed that AO7 could be decolorized within $6 \mathrm{~h}$ with a maximum decolorization of $98.34 \%$, while the consortium NYC-1 required more time (24 h) to achieve $83 \%$ decolorization of RB81 dye (Additional file 1: Table S1). To fully understand the mechanism, further study was carried out using AO7. Clearly, autoclaved cells of the constructed consortium NYC-1 and its individual yeast strains could not exhibit any decolorization of $\mathrm{AO} 7$, indicating the biological mechanisms of $\mathrm{AO} 7$ decolorization rather than adsorption.

\section{Effect of initial dye concentration on decolorization performance}

The decolorization of dye AO7 was greatly influenced by dye concentration. More than $98 \%$ of AO7 decolorization was achieved by NYC-1 consortium within $3 \mathrm{~h}$. However, the decolorization efficiency decreased with increasing AO7 concentration up to $250 \mathrm{mg} / \mathrm{L}$, achieving a maximum percentage decolorization of more than $92 \%$ within $18 \mathrm{~h}$ (Fig. 4a). The efficiency of dye decolorization and dye concentration are inversely correlated [13, 15, 22, 93]. In total, the level of azo dyes (10-200 mg/L) in wastewater and aquatic environments is aesthetically unpleasant [14] and cause several biological issues, therefore the effective treatment of azo dyes is of utmost importance before being discharged into the environment. As the highest concentrations of azo dyes tested in this study exceed the dye levels in wastewater and aquatic environments, the newly constructed oleaginous yeast consortium NYC-1, could potentially be utilized for bioremediation of wastewaters with high concentration of azo dyes.

\section{Effect of static and agitation conditions on decolorization performance}

The performance of NYC-1 consortium to decolorize $\mathrm{AO} 7$ under static and agitation conditions was tested and compared. Although oxygen has a significant effect on the physiological characteristics of the cells during their growth, the presence of oxygen can either favor or inhibit the microbial degradation of azo dyes [16, 94]. As depicted in Fig. 4b, the NYC-1 consortium decolorized AO7 efficiently (approximately complete decolorization) after $6 \mathrm{~h}$ of incubation under static conditions, whereas above $48 \%$ decolorization was achieved after $15 \mathrm{~h}$ of incubation under agitation conditions (120 rpm). This was probably due to the synergistic metabolic activities and production of enzymes by NYC-1 for the decolorization of $\mathrm{AO} 7$ dye under static conditions [95]. On the other hand, the growth of NYC-1 consortium under agitation conditions was fast as compared to its growth under static conditions, which was probably due to the facultative nature of yeast cells to grow anaerobically. Several studies reported efficient dye decolorization under static conditions when compared with agitation conditions [96-98]. The mechanism of azo dye biodegradation to its corresponding amines is initiated by the reduction of azo linkage using azoreductase [91]. Under agitation conditions, the excess of oxygen deprives azoreductase from receiving electrons required for the cleavage of azo linkage, while under static (microaerophilic) conditions, these electrons are readily available [99]. On the other hand, $\mathrm{MnP}$ is one of ligninolytic enzymes involved in dye decolorization processes. The MnP-producing fungal consortium successfully decolorized Cresol Red with 93\% efficiency after $144 \mathrm{~h}$ of incubation [100].

Decolorization performance of $150 \mathrm{mg} / \mathrm{L} \mathrm{AO} 7$ by the NYC-1 consortium as compared to its individual strains (Meyerozyma caribbica SSA1654, Meyerozyma 

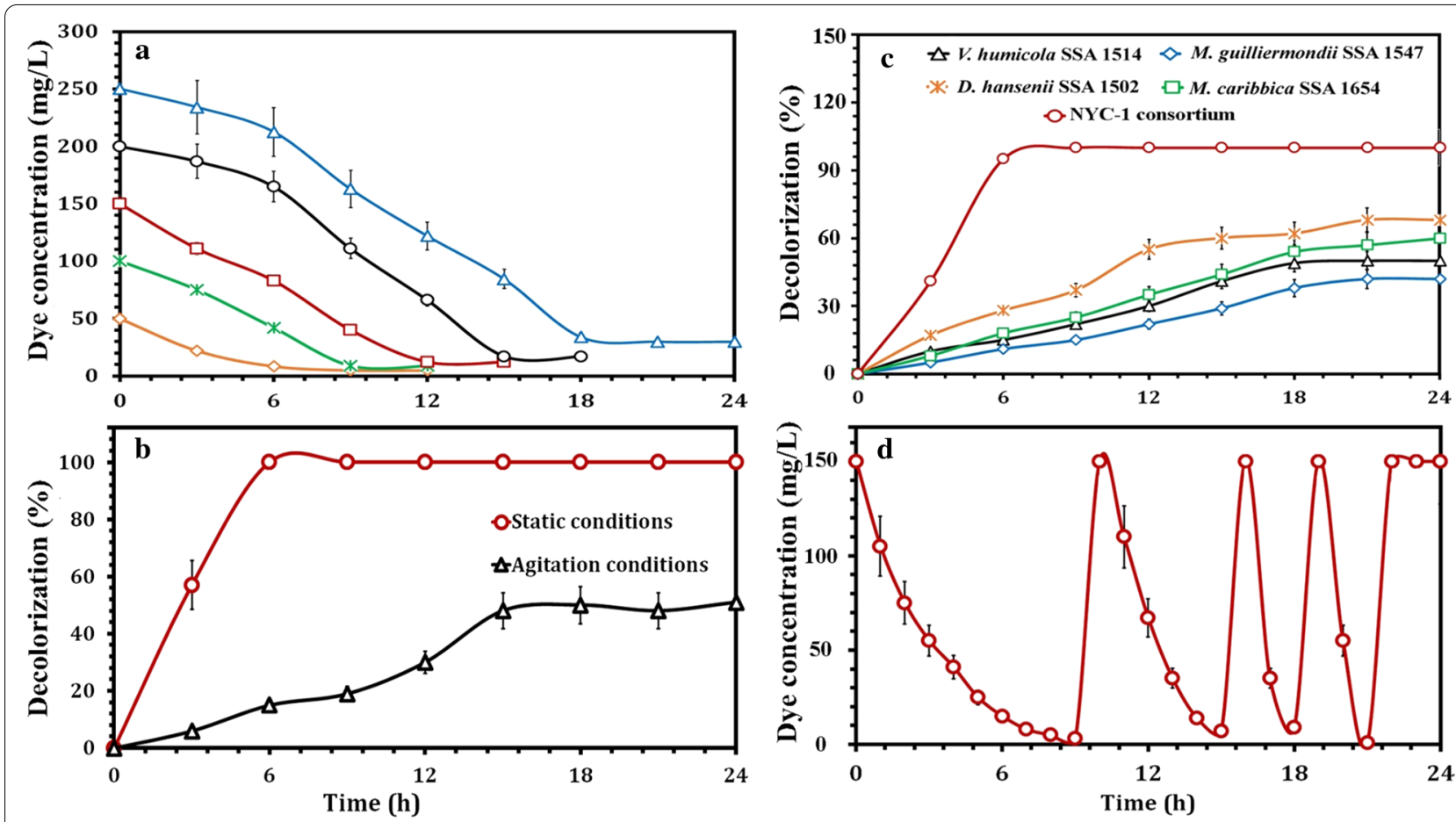

Fig. 4 Performance of NYC-1 consortium to decolorize AO7 at different dye concentrations (a) and under static and agitation conditions (b). Decolorization performance of $\mathrm{AO} 7$ (at a concentration of $150 \mathrm{mg} / \mathrm{L}$ ) by the NYC-1 consortium as compared to its individual strains (M. caribbica SSA1654, M. guilliermondii SSA1547, D. hansenii SSA1502, and V. humicola SSA1514) under static conditions (c). The repeated decolorization of AO7 (at a concentration of $150 \mathrm{mg} / \mathrm{L}$ ) by NYC-1 consortium under static conditions (d)

guilliermondii SSA1547, Debaryomyces hansenii SSA1502, and Vanrija humicola SSA1514) under static conditions was also evaluated. Clearly, SSA1654, SSA1547, SSA1502, and SSA1514 could decolorized the model dye tested. However, the decolorization of AO7 by NYC-1 was significantly higher than that of all individual strains (Fig. 4c), which was probably due to the concerted metabolic activities of the individual strains constituting NYC-1 consortium [15, 16, 101]. Furthermore, repeated spread plate studies revealed that no dominant yeast strain was observed over a period of nine months, suggesting the cooperation and synergistic metabolic activities among individual strains constituting NYC-1 consortium.

\section{Effect of repeated cycles of dye addition on decolorization performance}

The repeated decolorization of $\mathrm{AO} 7$ (at a concentration of $150 \mathrm{mg} / \mathrm{L}$ ) under static conditions was also studied. It has been observed that no significant variation in the decolorization of $\mathrm{AO} 7$ by NYC-1 consortium was observed after the fourth addition (Fig. 4d). The microorganism seems to initially use nutrient broth medium (as a carbon source), resulting in a slow decolorization in the first cycle of addition. With increase in number of microbial cells and less availability of nutrients in the culture medium, the microorganism seems to utilize the dye itself (as a carbon source), then gradually acclimatize to this new source, resulting in faster decolorization in the subsequent cycles of dye addition [102]. On the other hand, after the first cycle of dye addition, the formation of some metabolites as well as reduction in $\mathrm{pH}$ caused by the microorganism seems to be not only non-toxic to the microorganism, rather facilitating in dye biodegradation. Therefore, the microorganism once triggered for decolorization can use the dye as carbon source $[102,103]$. After the fourth cycle of dye and fresh medium additions, color removal was recovered, suggesting that the cell biomass recovered its full enzymatic activity and could be thus reused for multiple decolorization cycles and subsequently for large scale bioremediation purposes [18, 97].

\section{Effect of heavy metals on decolorization performance}

The performance of NYC-1 consortium to decolorize $\mathrm{AO} 7$ in the presence of several heavy metals $\left(\mathrm{MnSO}_{4}\right.$, $\mathrm{CuSO}_{4}$ and $\mathrm{FeSO}_{4} ; 100 \mathrm{mg} / \mathrm{L}$ each) was also studied. NYC-1 showed maximum decolorization of $98.76 \%$ with $\mathrm{Mn}$ after $24 \mathrm{~h}$ of incubation, which was probably due to the induction of $\mathrm{Mn}$ to $\mathrm{MnP}$ activity of NYC-1 consortium, resulting in the enhancement of the degradation of chemical nature of azo dye [104]. On the other hand, 
NYC-1 consortium revealed maximum decolorization of 87.34 and $65.18 \%$ with $\mathrm{Cu}$ and $\mathrm{Fe}$, respectively. In the presence of $\mathrm{Fe}$ at higher concentration, enzymatic activities may become unstable, hence affecting dye decolorization efficiency [105]. Our findings are in accordance with those previously reported by Singh and Dwivedi [22].

\section{Effect of supplementation of carbon and nitrogen sources on decolorization performance}

Carbon and nitrogen sources have an important influence on the extent of dye biodegradation. Since dyes are deficient in carbon, it seems necessary to supplement extra carbon or nitrogen source to assist biodegradation of azo dyes [106]. Therefore, in this study, the decolorization performance of $\mathrm{AO} 7$ by the yeast consortium NYC-1 was studied in the presence of different carbon sources (glucose, xylose, sucrose, maltose, and starch) and nitrogen sources (yeast extract, beef extract, peptone, urea, and sodium nitrate) to obtain efficient and faster dye decolorization. While trying to enhance decolorization performance of $\mathrm{AO} 7$ by NYC-1 consortium, extra carbon sources were supplied in the Bushnell Hass (BH) synthetic medium [18]. Clearly, the NYC-1 consortium showed lower decolorization performance (approximately $17 \%$ ) within $24 \mathrm{~h}$ in the BH medium since no cosubstrate was supplemented to this synthetic medium. Among different carbon sources tested for efficient decolorization of AO7, xylose and glucose were found to be better carbon sources with maximum decolorization percentage of 98.25 and $94.18 \%$, respectively. Monosaccharides, such as glucose and xylose, are easily available and effective carbon sources for microbial metabolism. Yang et al. [107] found that the addition of glucose improved the efficacy of azo dye degradation. However, addition of maltose (77.34\%), sucrose $(69.71 \%)$ and starch $(53.41 \%)$ found to be less effective to promote the decolorization performance of the NYC- 1 consortium as compared to the monosaccharides tested, which was probably due to the preference of the constructed yeast consortium in assimilating the added di- and polysaccharides over using $\mathrm{AO} 7$ dye as a carbon source $[98,108]$. Carbon sources provide energy for the growth and survival of the microorganisms together with their importance as electron donors, which are necessary for the breakage of the azo linkage [109]. During the decolorization process, the generated reducing equivalents, such as Flavin nucleotide (FAD), are transferred to the dye. Such reducing equivalents work as an electron shuttle between the dye and the NADH-dependent azo reductase during the electron transport chain of the microbial metabolism [110]. The decolorization performance of AO7 by the yeast consortium NYC-1 in the presence of nitrogen sources was also studied. The maximum decolorization percentage was observed in the presence of yeast extract (100\%), and peptone (97.15\%), within $24 \mathrm{~h}$. Yeast extract and peptone were reported to trigger the expression of $\mathrm{NADH}$, which acts as an electron donor for the reduction of azo dyes, and thus decolorize the dye effectively [111]. The addition of urea and sodium nitrate to the $\mathrm{BH}$ medium strongly inhibited AO7 decolorization by 44.32 and $38.80 \%$, respectively, while no decolorization was observed in the presence of ammonium chloride within $24 \mathrm{~h}$, which was probably due to their inhibitory effect on the enzyme systems involved in the dye decolorization process [112].

\section{Effect of co-substrate supplementation on decolorization performance}

The search for cheaper supplementary sources, such as agricultural wastes, would be essential to enhance process efficiency. In this regard, the decolorization performance of $\mathrm{AO} 7$ in the presence of extracts of agro-wastes was also evaluated. The highest decolorization performance by the $\mathrm{MnP}$-producing yeast consortium NYC-1 was observed with rice straw (92.33\%), sorghum husk (86.17\%), wheat bran $(72.59 \%)$, and rice stalk (59.83\%). Saratale et al. [113] and Jadhav et al. [114] reported that the presence of lignocellulosic substrates enhances decolorization through effective production of ligninolytic enzymes. Similar findings were reported by Saratale et al. [115] who found that supplementation with rice husk and rice straw extract enhanced the decolorization performance of the developed bacterial consortium GR on Scarlet R. The significant dye bio-decolorization in the presence of agricultural residues (e.g. wheat bran) in basal medium was probably due to the presence of certain components in wheat bran, which act as electron donors for the decolorization of azo dyes [116]. In total, supplementation of the cultivation medium with agro-wastes could enhance decolorization of $\mathrm{AO} 7$ by the NYC-1 consortium, along with producing ligninolytic enzymes. On the other hand, the addition of bagasse extract to the $\mathrm{BH}$ medium strongly inhibited $\mathrm{AO} 7 \mathrm{decol}-$ orization by $28.62 \%$, which was probably due to the production of alcohols or volatile organic acids as electron donors for reducing the dye. Lastly, no decolorization was observed in the presence of soybean husk and corn stalk, which was probably due to their inhibitory effects on microbial enzyme systems involved in dye decolorization. Therefore, it could be concluded that the use of lignocellulosic agro-wastes (rice straw, sorghum husk and wheat bran) instead of pure co-substrates (yeast extract, peptone, xylose, glucose and maltose) for the enhancement of $\mathrm{AO} 7$ decolorization represents an inexpensive 
and eco-friendly process, concurrently providing a solution to the challenge of disposal of agro-wastes that are present in huge quantities worldwide [98].

\section{Effect of dye on the fatty acid profile of NYC-1 consortium} Bioremediation of textile wastewater is an emerging technology, which uses microorganisms (e.g. bacteria, filamentous fungi, yeasts, and algae) for the treatment of dyes. Among these microorganisms, oleaginous yeasts have received increasing attention for efficient degradation of textile wastewater and successive accumulation of fatty acids which can be extracted and used for biodiesel production. Therefore, this study might be the first to explore the efficacy of a MnP-producing oleaginous yeast consortium for coupling dye biodegradation and biodiesel production. The extracted lipids of the AO7degraded NYC-1 consortium were compared with that of the control (NYC-1 consortium). Clearly, a decrease in the saturated fatty acid especially dodecanoic acid percentage as well as increased amount of other alkenes and alkanes in the dye-treated oleaginous yeast consortium compared with the control one were observed (Additional file 1: Table S2). On the other hand, the main physicochemical properties of biodiesel produced by AO7-degraded NYC-1 consortium were estimated and compared with the ASTM biodiesel standard (US) and diesel standard (Additional file 1: Table S3). In this study, the biodiesel extracted from NYC-1 consortium showed a better density as compared with that of jatropha [117], the marine cyanobacteria Synechococcus sp. [118], and Geitlerinema sp. TRV27 [119]. In addition, kinematic viscosity of the biodiesel extracted from NYC-1 consortium $\left(4.38 \mathrm{~mm}^{2} / \mathrm{s}\right)$ was quite similar to that of Geitlerinema sp. TRV27 and Synechococcus sp., which were found to be 3.36 and $3.13 \mathrm{~mm}^{2} / \mathrm{s}$, respectively $[119,120]$. The biodiesel extracted from NYC-1 consortium showed less acid value $(0.273 \mathrm{mg}$ of $\mathrm{NaOH} / \mathrm{g}$ of oil) as compared to jatropha oil diesel (5.31 mg of NaOH/g of oil) [121], and sorghum oil diesel ( $0.434 \mathrm{mg}$ of $\mathrm{NaOH} / \mathrm{g}$ of oil) [120]. As shown in Additional file 1: Table S3, cetane value of the biodiesel extracted from NYC-1 consortium was found to be 53 as compared to that of palm (62), sunflower (49), rapeseed (54) and peanut (54) [122]. Clearly, the physicochemical properties of the biodiesel produced by the dye-treated NYC-1 were found to be within the standard limits.

\section{$\mathrm{MnP}$ and Lac activities under different concentration of $\mathrm{AO} 7$ azo dye}

Except azoreductase, ligninase enzymes $\mathrm{MnP}$ and Lac are effective agents for dye biodegradation, generating more eco-friendly products [123]. Several Lac-producing fungal isolates, which degraded various dyes of different chemical structures, have effectively catalyzed the phenolic substrate oxidation of dye compound using oxygen as electron acceptor [124]. The application of such biological agents promotes an eco-friendly technology as well as the reduction in chemical load [125]. As depicted in Table 5, the activity of Lac enzyme increased with increasing the concentration of $\mathrm{AO} 7$, which ranged from $0.69 \pm 0.16$ to $1.53 \pm 0.12 \mu \mathrm{m} / \mathrm{L}$ after $120 \mathrm{~h}$ of dyedegrading NYC-1 consortium, suggesting that Lac enzyme could be effectively involved in the biodegradation of $\mathrm{AO} 7$ by the oleaginous consortium developed in this study. Pandey et al. [126] reported the effectiveness of various oxidoreductase enzymes in the decolorization process, converting parent dyes into less toxic compounds. Similar to Lac, MnP activity also increased with increasing the concentration of $\mathrm{AO} 7$, which ranged from $1.66 \pm 0.011$ to $4.56 \pm 0.02 \mu \mathrm{m} / \mathrm{L}$ after $120 \mathrm{~h}$ of dye-degrading NYC-1 consortium, hence inducing the degradation of AO7 (Table 5). Gao et al. [127] reported that $\mathrm{MnP}$ related to lignolytic peroxidase family is able to mineralize azo dyes via redox reaction, which oxidizes phenolic compounds with conversion of $\mathrm{Mn}^{+2}$ to $\mathrm{Mn}^{+3}$. On the other hand, $\mathrm{H}_{2} \mathrm{O}_{2}$ content increased with increasing the concentration of $\mathrm{AO} 7$, reaching $6.0 \pm 0.07 \mathrm{nM} / \mathrm{g}$ $\mathrm{FW}$ at $500 \mathrm{mg} / \mathrm{L}$ dye concentration, then decreased, achieving $2.0 \pm 0.03 \mathrm{nM} / \mathrm{g} \mathrm{FW}$ at a $\mathrm{AO} 7$ concentration of $1000 \mathrm{mg} / \mathrm{L}$ after $120 \mathrm{~h}$ of dye-degrading NYC-1 consortium. It has been reported that increased amount of $\mathrm{H}_{2} \mathrm{O}_{2}$ as cofactors is required for activating peroxidase enzyme but at a certain time, resulting in dye biodegradation by MnP, then any further increase can inhibit the enzyme activity [128].

\section{Possible dye degradation pathway coupled with biodiesel production}

The mechanism of azo dye biodegradation and successive production of biodiesel was proposed based on GCMS technique, ligninase activities and previous studies (Fig. 5). According to our proposal, the first step in the

Table 5 Ligninase activities and $\mathrm{H}_{2} \mathrm{O}_{2}$ content under different concentrations of dye-treated consortium NYC-1

\begin{tabular}{llll}
\hline $\begin{array}{l}\text { AO7 } \\
\text { concentration } \\
\text { (mg/L) }\end{array}$ & MnP activity $(\mu \mathrm{m} / \mathbf{L})$ & Laccase $(\mu \mathrm{m} / \mathbf{L})$ & $\begin{array}{l}\mathrm{H}_{2} \mathbf{O}_{2} \text { content } \\
(\mathbf{n M} / \mathbf{g ~ F W})\end{array}$ \\
\hline 0.0 & $1.66 \pm 0.011^{\mathrm{a}, \mathrm{b}}$ & $0.69 \pm 0.16$ & $0.91 \pm 0.07$ \\
100 & $2.48 \pm 0.015$ & $0.40 \pm 0.11$ & $4.0 \pm 0.05^{\mathrm{a}, \mathrm{c}}$ \\
500 & $3.77 \pm 0.011$ & $0.96 \pm 0.14$ & $6.0 \pm 0.07^{\mathrm{a}, \mathrm{c}}$ \\
1000 & $4.56 \pm 0.020^{\mathrm{a}, \mathrm{b}}$ & $1.53 \pm 0.12$ & $2.0 \pm 0.03$ \\
\hline
\end{tabular}

The values are mean of three independent experiments; ${ }^{a}$ Significant difference versus laccase; ${ }^{\text {b }}$ Significant difference versus $\mathrm{H}_{2} \mathrm{O}_{2}$ content; ${ }^{\text {CSignificant }}$ difference versus $\mathrm{MnP}$ activity 
degradation mechanism of $\mathrm{AO} 7$ by the developed oleaginous yeast consortium NYC-1 is the decolorization of AO7 by asymmetric cleavage of the azo bond $(-\mathrm{N}=\mathrm{N}-)$ as catalyzed by Lac, producing two intermediates namely (4-sulfophenyl)diazenyl and naphthalen-2-ol (Fig. 5). The first intermediate is subjected to oxidative desulfonation, resulting in the formation of phenyl diazene, which is an unstable radical and it might rapidly lose nitrogen as gas molecule. Hence, phenol is formed as a result of the nucleophilic substitution of hydroxyl radical on the aromatic ring. The formation of hexanoic acid $\left(\mathrm{R}_{t}, 5.08\right.$; $\mathrm{M}+\mathrm{H}^{+}, 60$ ) might be due to the oxidative ring cleavage

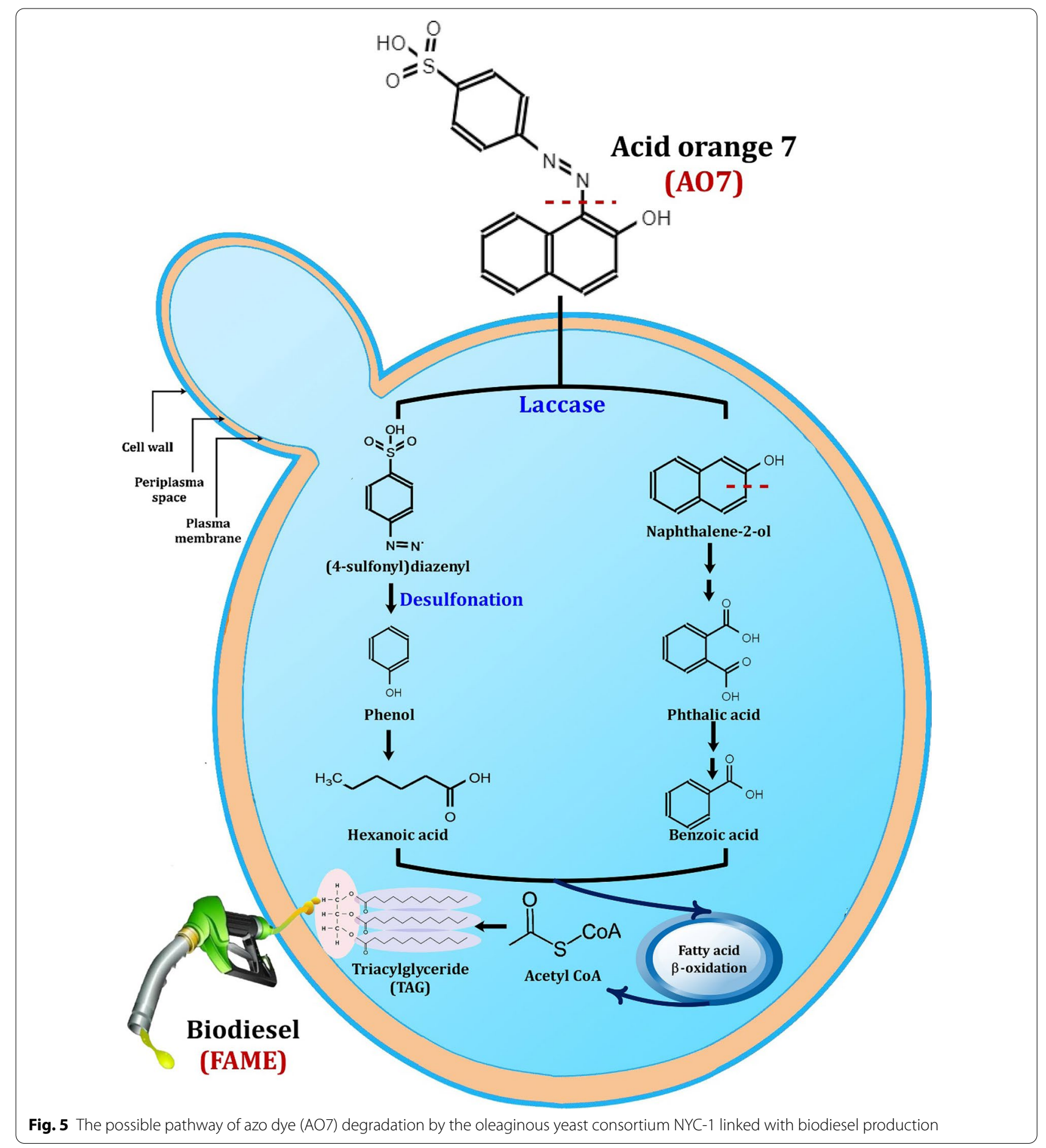


of phenols, which are the natural substrates for Lac. Hexanoic acid is a carboxylic acid with the general formula $\mathrm{C}_{5} \mathrm{H}_{11} \mathrm{COOH}$. It is a non-toxic fatty acid found naturally in many food products available for human consumption, various animal fats and oils. On the other hand, the second intermediate (naphthalen-2-ol) is subjected to aromatic ring cleavage, producing phthalic acid $\left(\mathrm{R}_{t}, 11.02\right.$; $\left.\mathrm{M}+\mathrm{H}^{+}, 149\right)$, which is further oxidized to form benzoic acid $\left(\mathrm{R}_{t}, 7.45 ; \mathrm{M}+\mathrm{H}^{+}, 105\right)$ as depicted in Fig. 5. Zhang et al. [129] reported that the addition of $p$-methyl benzoic acid was able to increase the growth of oleaginous yeasts, resulting in higher lipid accumulation. The intermediate products (4-sulfophenyl) diazenyl and naphthalen-2-ol may directly or indirectly enter fatty acid $\beta$-oxidation reactions to produce $\mathrm{NADH}_{2}$ and $\mathrm{FADH}_{2}$, which may be used in ATP synthesis. Besides, acetyl CoA is a precursor necessary for TAG synthesis and the accumulated TAG can be effectively transesterified to further produce biodiesel. Similar pathway was also observed for the decolorization of synthetic dyes, such as Remazol brilliant blue, by Pleurotus ostreatus HAUCC 162 Lac [130]. The formation of phenyl diazene radical was also observed as a result of biodegradation of phenolic azo dyes based on fungal Lac [131]. AO7 oxidation by Lac of the NYC-1 consortium was subjected to reactive free radicals as illustrated above (Fig. 5). Besides, MnP catalyzes a $\mathrm{H}_{2} \mathrm{O}_{2}$-dependent oxidation of $\mathrm{Mn}^{2+}$ to form highly reactive $\mathrm{Mn}^{3+}$, which subsequently oxidizes the phenolic parts of lignin to produce free radicals [132]. Therefore, the mechanism proposed for the degradation of $\mathrm{AO} 7 \mathrm{azo}$ dye by the NYC-1 consortium with successive biodiesel production revealed the formation of phenol-based products thereby avoiding the formation of toxic aromatic amines (Fig. 5).

\section{Conclusion}

Wood-feeding termite symbionts represent a significantly rich source of yeasts which can be isolated and utilized for various applications, including wastewater remediation and production of energy and added-value products. Owing to yeasts' multiple valuable properties, such as high enzymatic activity, tolerance to ligninderived metabolites and lipid accumulation, a combined process including azo dye degradation and biodiesel production is proposed, in the framework of the present study. First, 38 strains were isolated and screened for $\mathrm{MnP}$ production, along with lipid accumulation. The highest lipid content determined was $47.25 \%$ in case of Meyerozyma caribbica, while the produced biodiesel was in compliance with international standards. Furthermore, Meyerozyma caribbica, Meyerozyma guilliermondii, Debaryomyces hansenii, and Vanrija humicola were identified for the first time as cellulase, xylanase, and lipase producers. Subsequently, the constructed consortium NYC-1 was evaluated for azo dyes remediation, while static conditions, addition of Mn, supplementation with xylose and glucose as carbon sources, yeast extract and peptone as nitrogen sources, or rice straw as an agro-waste co-substrate enhanced decolorization activity. Last, a dye degradation pathway coupled to biodiesel production was proposed, which included the formation of phenol-based products instead of toxic metabolites. In total, this study might be the first to explore the application of a $\mathrm{MnP}$ and lipid-producing consortium for coupling dye degradation and biodiesel production.

\section{Methods}

\section{Dyestuff, chemicals and agricultural wastes}

The chemicals, reagents, and azo dyes used in this study were purchased from Sigma-Aldrich (St. Louis, MO, USA). All chemicals and reagents were of analytical grade. The azo dyes tested in this study were AO7 $\left(\lambda_{\max }=484 \mathrm{~nm}\right), \quad$ RB5 $\quad\left(\lambda_{\max }=595 \mathrm{~nm}\right)$, RB19 $\left(\lambda_{\max }=592 \quad \mathrm{~nm}\right), \quad R$ R120 $\quad\left(\lambda_{\max }=537 \quad \mathrm{~nm}\right)$, RG19 $\left(\lambda_{\max }=630 \mathrm{~nm}\right), \quad$ MO $\quad\left(\lambda_{\max }=465 \quad \mathrm{~nm}\right)$, MR $\left(\lambda_{\max }=424 \mathrm{~nm}\right), \quad$ SGR $\left(\lambda_{\max }=511 \mathrm{~nm}\right), \quad$ RV5 $\left(\lambda_{\max }=530 \mathrm{~nm}\right)$, and RB81 $\left(\lambda_{\max }=581 \mathrm{~nm}\right)$. To optimize culture conditions for the enhancement of AO7 decolorization, different carbon sources (glucose, xylose, sucrose, maltose, and starch) and nitrogen sources (yeast extract, beef extract, peptone, urea, and sodium nitrate) were used. Different agricultural wastes (sorghum husk, soybean husk, corn stalk, rice stalk, rice straw, bagasse, and wheat bran) obtained from local farmers and industries (Zhenjiang, China) were also used in this study to evaluate their effects on the dye decolorization of AO7.

\section{Screening and enrichment process}

The wood-feeding termite, $R$. chinenesis was collected from rotting wood trees (Wuhan, Hubei, China), while C. formosanus termite samples were collected from three different sites at Suzhou, Nanjing and Zhenjiang (China). Isolation of yeasts from insect gut symbionts was performed following Suh and Blackwell [133]. Briefly, the surface of termite species was sterilized with $70 \%$ ethanol for $1 \mathrm{~min}$ before dissection. Then, guts of the collected termite samples were removed aseptically, following with homogenization using saline solution $(0.85 \%, w / \mathrm{v} \mathrm{NaCl})$. To screen and characterize stable peroxidase-producing yeasts capable of coupling azo dye biodegradation and biodiesel production, an enrichment process was performed (Fig. 6). Since a high carbon to nitrogen $(\mathrm{C} / \mathrm{N})$ ratio improves lipid accumulation, $\mathrm{N}$-limited medium was used following the protocol of Suutari et al. [134]. Briefly, isolation of yeasts was carried out in a conical flask $(100 \mathrm{~mL})$ containing $40 \mathrm{~mL}$ 


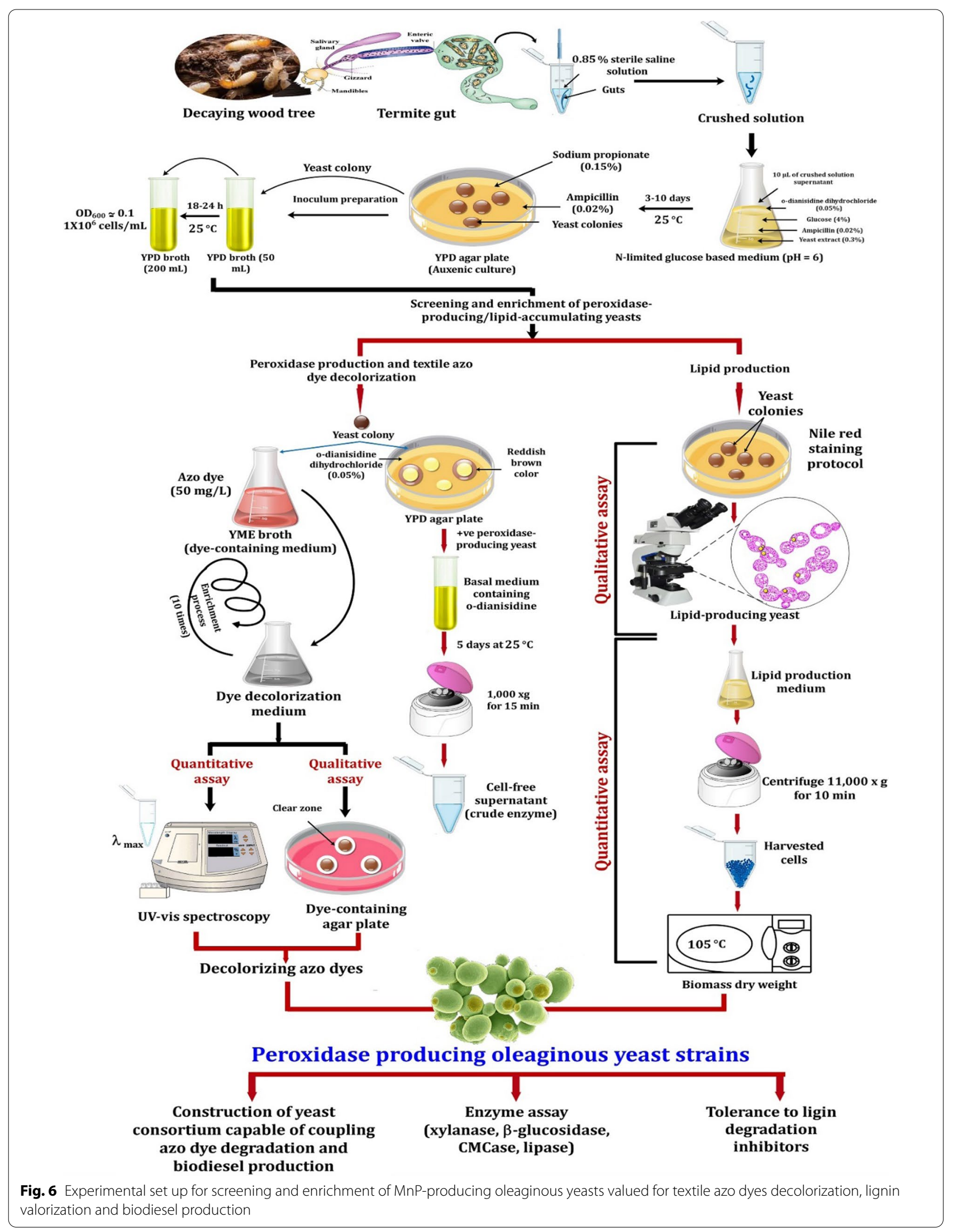


of N-limited glucose-based medium $\left(6.8 \mathrm{~g} / \mathrm{L} \mathrm{KH}_{2} \mathrm{PO}_{4}\right.$, $2.45 \mathrm{~g} / \mathrm{L} \quad \mathrm{NaH}_{2} \mathrm{PO}_{4}, 1.72 \mathrm{~g} / \mathrm{L} \mathrm{MgSO}_{4} \cdot 7 \mathrm{H}_{2} \mathrm{O}, 0.067 \mathrm{~g} / \mathrm{L}$ $\mathrm{MnSO}_{4} \cdot 7 \mathrm{H}_{2} \mathrm{O}$, and $0.2 \mathrm{~g} / \mathrm{L} \mathrm{CaCl} \cdot 2 \mathrm{H}_{2} \mathrm{O}$ ) supplemented with $0.5 \mathrm{~g} / \mathrm{L}$ o-dianisidine dihydrochloride (a precursor of many azo dyes). Glucose (C-source) was added to the medium at a final concentration of $40 \mathrm{~g} / \mathrm{L}$, while yeast extract $(3.0 \mathrm{~g} / \mathrm{L})$ was used as the only $\mathrm{N}$-source, yielding a $\mathrm{C} / \mathrm{N}$ ratio of around 40 . A volume of $10 \mu \mathrm{L}$ of the crushed gut solutions was inoculated in the prepared flasks containing $\mathrm{N}$-limited glucose-based medium. Then, flasks were incubated at $25^{\circ} \mathrm{C}$ for $3-10$ days with an agitation speed of $150 \mathrm{rpm}$. A total of 75 yeast colonies were isolated on YPD medium (10 g/L yeast extract, $20 \mathrm{~g} / \mathrm{L}$ peptone, $10 \mathrm{~g} / \mathrm{L}$ dextrose and $20 \mathrm{~g} / \mathrm{L}$ agar) containing $0.2 \mathrm{~g} / \mathrm{L}$ ampicillin (antibacterial agent) and $1.5 \mathrm{~g} / \mathrm{L}$ sodium propionate (antifungal agent).

\section{Isolates' identification and phylogenetic analysis}

Yeast isolates were identified by amplified rDNA gene sequencing following the procedures described earlier [39]. The isolated DNA was amplified using NL1/NL4 and ITS1/ITS4 primers, for D1/D2 and ITS regions, respectively. PCR amplification was performed as previously described [91]. Phylogenetic and evolutionary analyses were conducted in MEGA software version 7.0. The identification of yeast strains was performed based on nucleotide BLAST (http://www.ncbi.nlm.nih.gov/BLAST /) database.

\section{Peroxidase production}

Qualitative assay of peroxidase-production was determined on YPD agar plates supplemented with $0.5 \mathrm{~g} / \mathrm{L}$ o-dianisidine dihydrochloride and incubated at $25^{\circ} \mathrm{C}$, up to 3 days. The reddish-brown color change around yeast colonies, after flooding the plates with $0.4 \mathrm{mM} \mathrm{H}_{2} \mathrm{O}_{2}$, is positively correlated with the production of peroxidase enzyme. Subsequently, the peroxidase-producing yeast isolates, which showed a large reddish-brown color, were selected for enzyme production in basal medium contained (per liter): $1.0 \mathrm{~g}$ o-dianisidine, $1.5 \mathrm{~g}$ yeast extract, $15 \mathrm{~g}$ dextrose, $0.5 \mathrm{~g} \mathrm{KH}_{2} \mathrm{PO}_{4}, 0.5 \mathrm{~g} \mathrm{~K}_{2} \mathrm{HPO}_{4}$ and $0.5 \mathrm{~g}$ $\mathrm{NaCl}$. In addition, $\mathrm{MnSO}_{4} \cdot 4 \mathrm{H}_{2} \mathrm{O}(150 \mu \mathrm{M})$ was added to the basal medium to stimulate the production of MnP. The cultures were incubated at $25^{\circ} \mathrm{C}$ for 5 days, followed by centrifugation at $10,000 \times g$ for $15 \mathrm{~min}$ to obtain crude enzyme (Fig. 6).

\section{Determination of glucose residual, nitrogen assimilation and lipid production}

The isolated yeast colonies were qualitatively screened for lipid production by flooding the agar plates with $0.3 \%$ Sudan black B. After $30 \mathrm{~min}$, excess stain was rinsed with $70 \%$ ethanol. The putative oleaginous yeasts which retained the blue color were further confirmed for lipid accumulation using Sudan black B and Nile red staining protocols (Fig. 6). The qualitative assay for lipid production with Sudan black B was performed according to Sagia et al. [84] and the intracellular lipid droplets were stained blue when observed under light microscope. On the other hand, lipid detection by Nile red fluorimetry was achieved following the protocol described by Vyas and Chhabra [57]. Lipidproducing yeast cells were observed under a fluorescence microscope (Olympus BX35) with emission wavelength of $460-500 \mathrm{~nm}$.

Yeast isolates that were positive for lipid production were further quantitatively assessed through gravimetric analysis [55]. After 5 days of growth in lipid production medium at $25{ }^{\circ} \mathrm{C}$, biomass was harvested using a centrifuge (model 5418, Eppendorf, Germany) at $11.000 \times g$ for $10 \mathrm{~min}$ and subsequently the pelleted biomass was washed three times with $10 \mathrm{~mL}$ of distilled water and dried at $105^{\circ} \mathrm{C}$ until constant weight (Fig. 6). To quantify lipids in cell biomass at a dry weight basis, the sonicated cells were homogenized with $20 \mathrm{~mL}$ solvent mixture of chloroform and methanol $(2: 1 \mathrm{v} / \mathrm{v})$. After $30 \mathrm{~min}$ of incubation at room temperature, the upper phase was discarded, while the lower chloroform phase containing the lipids was mixed with $10 \mathrm{~mL}$ of solvent mixture into a pre-weighted container. Subsequently, the solvent was evaporated using a rotary evaporator, dried using a rotary vacuum pump (model SHZ-D-III) for $10 \mathrm{~min}$, cooled in a desiccator for $30 \mathrm{~min}$, then the container was weighted again and lipid yield ( $\mathrm{g}$ lipid/g biomass) was determined [135]. The parameters of biomass and lipid production were calculated using the following equations:

$$
\text { Biomass productivity }=\frac{\text { Cell dry mas }}{\text { Culture volume }}(\mathrm{g} / \mathrm{L})
$$

$$
\begin{aligned}
& \text { Lipid productivity } \\
& \qquad=\frac{\text { Lipid output }}{\text { Days required to achieve maximum lipid }}(\mathrm{g} / \mathrm{L} / \text { day })
\end{aligned}
$$

$$
\text { Lipid output }=\frac{\text { Mass of lipid }}{\text { Culture volume }}(\mathrm{g} / \mathrm{L})
$$$$
\text { Lipid content }=\frac{\text { Lipid output }}{\text { Biomass productivity }} \times 100(\%)
$$

$$
\begin{aligned}
Y_{\mathrm{L} / \mathrm{x}} & =\frac{\text { Lipid output }}{\text { Total biomass produced }}(\mathrm{g} / \mathrm{g}) \\
Y_{\mathrm{X} / \mathrm{S}} & =\frac{\text { Total biomass produces }}{\text { Consumed substrate }}(\mathrm{g} / \mathrm{g})
\end{aligned}
$$




$$
Y_{\mathrm{L} / \mathrm{S}}=\frac{\text { Cellular lipids produced }}{\text { Consumed substrate }}(\mathrm{g} / \mathrm{g})
$$

Furthermore, the supernatant derived after cell harvesting was used for measuring the content of glucose and nitrogen throughout culturing time. Quantitative analysis of reducing sugars, such as glucose, was performed using the 3,5-Dinitrosalicylic acid method [136]. The concentration of ammonia in the culture supernatant was estimated to determine nitrogen assimilation following the method described by Gomez-Alonso et al. [137]. Briefly, derivatization was performed in the supernatant followed by ultra-performance liquid chromatography (UPLC, Waters, Milford, USA) equipped with the analytical column (Acquity BEH C18, Waters, Milford, USA). Before injection, samples were filtered using nylon filters $(0.2 \mu \mathrm{m}$ pore size $)$.

\section{Characterization of extracted lipids and biodiesel properties}

The extracted neutral lipids were analyzed by TLC using a K6 silica gel plate (Merck, India). The mixture of hexane: diethyl-ether: methanol: acetic acid (78:17:3:2, v/v) was used as solvent system for analyzing TAG. Olive oil was used as positive control of vegetable TAG for plate migration. TLC plates were then exposed to iodine vapor to detect lipids [138]. The extracted lipid was also subjected to methanolysis following the protocol described by Morrison and Smith (1964). The FAME obtained by transesterification was further analyzed on a gas chromatography system (Agilent Technologies, France, M-6890) equipped with a flame ionization detector FID. An aliquot $(2 \mu \mathrm{L})$ was injected employing a HP-5 capillary column ( $30 \mathrm{~m}, 0.32 \mathrm{~mm}, 0.25 \mu \mathrm{m})$. Helium was used as carrier gas with a flow rate of $1 \mathrm{~mL} / \mathrm{min}$. Detector temperature was set at $290{ }^{\circ} \mathrm{C}$, while the temperature of injector was $270{ }^{\circ} \mathrm{C}$. The column temperature was set at $50{ }^{\circ} \mathrm{C}$, increased to $180^{\circ} \mathrm{C}$ at a rate of $13^{\circ} \mathrm{C} / \mathrm{min}$ and held for $3 \mathrm{~min}$, then the temperature was increased to $280{ }^{\circ} \mathrm{C}$ at a rate of $10{ }^{\circ} \mathrm{C} / \mathrm{min}$ and held for $4 \mathrm{~min}$. The retention times of the produced FAME were compared with those of known standards (Sigma-Aldrich, St. Louis, MO, USA). The fatty acids composition of each sample was determined in triplicate. Also, the quality of the biodiesel was determined in this study. For this purpose, the main physicochemical properties were studied, including $\mathrm{CN}$, IV, SV, $v, \rho$, OS, LCSF and DU [61].

\section{Development of yeast consortium NYC-1}

To construct a stable MnP-producing oleaginous yeast consortium capable of decolorizing textile azo dyes and successive production of biodiesel, the enrichment culture technique was performed as previously described by
Al-Tohamy et al. [13] with minor modifications. Briefly, the MnP-producing yeast isolates that were positive for lipid production were inoculated into $100 \mathrm{~mL}$ Erlenmeyer flasks containing $30 \mathrm{~mL}$ YME medium $(3.0 \mathrm{~g} / \mathrm{L}$ yeast extract, $3.0 \mathrm{~g} / \mathrm{L}$ malt extract, $5.0 \mathrm{~g} / \mathrm{L}$ peptone, and $10 \mathrm{~g} / \mathrm{L}$ dextrose) amended with different azo dyes at an initial concentration of $50 \mathrm{mg} / \mathrm{L}$ and incubated at $25{ }^{\circ} \mathrm{C}$ under static conditions. Once decolorization was observed, an aliquot $(5 \mathrm{~mL})$ was re-inoculated into a fresh dye-containing medium for additional round of culturing transfer. For 10 generations of successive enrichment process, a stable yeast consortium with high decolorization performance was obtained (Fig. 6). The dye decolorization procedures were also repeated on agar plates supplemented with $50 \mathrm{mg} / \mathrm{L}$ dye and incubated at $25^{\circ} \mathrm{C}$ for $48 \mathrm{~h}$. The fastest-growing yeast that was capable of decolorizing various azo dyes as well as showing a high ratio of decolorization zone to the yeast colony diameter was isolated for phenotypic and genotypic characterization [39], followed by consortium construction [101]. For constructing a novel yeast consortium, designated as NYC-1, $100 \mu \mathrm{L}$ of overnight grown culture of each individual yeast strain was inoculated separately into $100 \mathrm{~mL}$ Erlenmeyer flasks containing $30 \mathrm{~mL}$ YPD broth and incubated at $25{ }^{\circ} \mathrm{C}$ under static conditions for $24 \mathrm{~h}$. The individual yeast strains were then mixed in equal proportion ( $500 \mu \mathrm{L}$; OD of 0.2 ) to maintain the same cell count in the yeast consortium NYC-1 as well as in the pure culture.

\section{Enzyme assays}

MnP activity was measured as previously described [139] using guaiacol as mediator. The obtained crude enzyme extract $(600 \mu \mathrm{L})$ was mixed with $500 \mu \mathrm{L}$ of $0.1 \mathrm{M}$ guaiacol, $500 \mu \mathrm{L}$ of sodium tartrate buffer $(100 \mathrm{mM}, \mathrm{pH}$ 5), 50 $\mu \mathrm{L}$ of $\mathrm{H}_{2} \mathrm{O}_{2}$, and $500 \mu \mathrm{L}$ of $\mathrm{MnSO} 4$, and then incubated at $30{ }^{\circ} \mathrm{C}$ for $5 \mathrm{~min}$. The appearance of brown color after the addition of guaiacol is the indicator for the presence of peroxidase enzymes. The absorbance at $465 \mathrm{~nm}$ was monitored using a UV-vis spectrophotometer (Shimadzu UV2600, Japan). Lac activity was determined following the method described by Adnan et al. [140], using guaiacol as the corresponding substrate. The reaction mixture containing $500 \mu \mathrm{L}$ of guaiacol solution was mixed with $1500 \mu \mathrm{L}$ of sodium acetate buffer $(10 \mathrm{mM}, \mathrm{pH}$ 5) and $500 \mu \mathrm{L}$ of filtered crude enzyme extract, and then incubated at $30{ }^{\circ} \mathrm{C}$ for $3 \mathrm{~min}$. The absorbance at $450 \mathrm{~nm}$ was monitored using a UV-vis spectrophotometer (Shimadzu UV2600, Japan). $\mathrm{H}_{2} \mathrm{O}_{2}$ content was determined as previously described [141]. Endo- $\beta$-1,4-glucanase (CMCase) and xylanase activities were determined by the 3,5-Dinitrosalicylic acid method [136] using CMC $(1 \% \mathrm{w} / \mathrm{v})$ and xylan, respectively [39]. For the enzymatic activity of $\beta$-glucosidase, $p$-nitrophenyl glucopyranoside 
( $p$-NPG) was used as the corresponding substrate $(5 \mathrm{mM}$, $\mathrm{pH} 5)$ according to the method of Ali et al. [16]. Lipase activity was measured using $p$-nitrophenyl palmitate $(p$ NPP) as the corresponding substrate [18]. One unit of enzyme activity was defined as the amount of enzyme equivalent to the release of $1.0 \mu \mathrm{mol}$ of the reaction product per minute, under the assay conditions.

\section{Tolerance to lignin degradation inhibitors}

The peroxidase-producing oleaginous yeast strains were tested for their tolerance to common inhibitors in lignocellulosic hydrolysates. Each yeast strain was inoculated in Erlenmeyer flasks with sterile yeast nitrogen base broth [142], containing 1\% glucose and supplemented with different concentrations of furfural, HMF, syringaldehyde, vanillin, and 4-hydroxybenzaldehyde. The flasks were incubated at $25^{\circ} \mathrm{C}$ and $\mathrm{pH} 5$ for 5 days. The tolerance of yeast strains to the inhibitors tested was measured at $600 \mathrm{~nm}$ and it was expressed as DCW $(\mathrm{g} / \mathrm{L})$. Percentage decrease in yeast growth due to the inhibitors was calculated compared to growth without inhibitors, used as control.

\section{Azo dye decolorization experiments}

Quantitative assay of dye decolorization was performed following the method described previously [14], with a minor modification. Briefly, the respective $\lambda_{\max }$ of the different azo dyes was measured individually with a UV-vis spectrophotometer (Shimadzu UV2600, Japan). Un-inoculated control was included during the decolorization experiments. All experiments were carried out in triplicate. The above decolorization protocol was also followed while evaluating the efficacy of the NYC-1 consortium in the decolorization of $\mathrm{AO} 7$ at increasing initial dye concentrations (50-2000 mg/L), static and agitation conditions, repeated cycles of dye addition, and in the presence of heavy metals $\left(\mathrm{MnSO}_{4}, \mathrm{CuSO}_{4}\right.$ and $\left.\mathrm{FeSO}_{4}\right)$. Dye decolorization performance was also assessed in the presence of different carbon sources (glucose, xylose, sucrose, maltose, and starch) and nitrogen sources (yeast extract, beef extract, peptone, urea, and sodium nitrate) with the addition of $0.5 \%(\mathrm{w} / \mathrm{v})$ of each source to the culture medium. To study the effect of agricultural waste as co-substrates supplementation on the decolorization of AO7, different agricultural wastes (sorghum husk, soybean husk, corn stalk, rice stalk, rice straw, bagasse, and wheat bran) were used in this study $(0.5 \mathrm{~mL}$ extract of $0.5 \%$ boiled agricultural residue). The effect of $\mathrm{AO} 7$ on the fatty acid profile of NYC-1 consortium was assessed by comparing the chemical profile of dye-decolorizing biomass with the control. After $120 \mathrm{~h}$ of incubation, the dye-decolorizing biomass was extracted using hexane solvent solution, and then transesterified by alkali catalyst method for lipid analysis.

\section{Identification of dye degradation metabolites}

The products of AO7 degradation by NYC-1consortium were analyzed by gas chromatography/mass spectrometry (GC-MS). The samples were extracted with dichloromethane (DCM) using liquid to liquid extraction at various $\mathrm{pH}$ values to neutralize any charged compounds, such as phenolics and amines. The extracted metabolites were analyzed using a gas chromatograph system (Agilent) equipped with a Restek Rxi-5 ms capillary column. A sample volume $(1 \mu \mathrm{L})$ was injected in split mode with injector temperature of $250{ }^{\circ} \mathrm{C}$. The flow rate of helium used as a carrier gas was $1.1 \mathrm{~mL} / \mathrm{min}$. The initial temperature was held at $40{ }^{\circ} \mathrm{C}$ for $1 \mathrm{~min}$, then ramped at $10{ }^{\circ} \mathrm{C}$ per min until $340^{\circ} \mathrm{C}$ (hold time $10 \mathrm{~min}$ ). Electron ionization (EI) was used with MS source temperature at $230{ }^{\circ} \mathrm{C}$ and Quad temperature at $150{ }^{\circ} \mathrm{C}$. The metabolites were identified by comparison of the obtained spectra with those stored in the NIST mass spectra database.

\section{Statistical analysis}

All experiments were carried out in triplicate and results were analyzed with the Minitab software version 19.2020.1 (Minitab Inc., US) and NCSS 2020 (NCSS, LIC, Utah, USA). The obtained data were analyzed statistically to determine the degree of significance using one-way analysis of variance (ANOVA) with Tukey-Kramer multiple comparisons and $t$-Student's tests at $p$-value $\leq 0.05$.

\section{Supplementary Information}

The online version contains supplementary material available at https://doi. org/10.1186/s13068-021-01906-0.

Additional file 1: Table S1. Performance of the constructed yeast consortium NYC-1 on decolorizing different azo dyes. Table S2. Hydrocarbon fractions of hexane extract of the AO7-degraded NYC-1 consortium as analysed by GC-MS for biodiesel production. Table S3. Physicochemical properties of biodiesel produced by AO7-degraded NYC-1 consortium.

\section{Abbreviations}

TAG: Triacylglycerides; FAMEs: Fatty acid methyl esters; MUFA: Mono-unsaturated fatty acid; SFA: Saturated fatty acid; PUFA: Poly-unsaturated fatty acid; CN: Cetane number; IV: Iodine value; SV: Saponification value; v: Kinematic viscosity; $\rho$ : Density; OS: Oxidative stability; LCSF: Long-chain saturation factor; DU: Degree of unsaturation; DCW: Dry cell weight; AMP: Adenine-mono-phosphate; IMP: Inosine-mono-phosphate; $\mathrm{ClO}_{2}$ : Chlorine dioxide; TCA: Tricarboxylic acid; Lac: Laccase; LiP: Lignin peroxidase; MnP: Manganese peroxidase; YPD: Yeast peptone dextrose; BH: Bushnell Hass; FAD: Flavin nucleotide; AO7: Acid Orange 7; RG19: Reactive Green 19; SGR: Scarlet GR; RB5: Reactive Black 5; MO: Methyl Orange; RB19: Reactive Blue 19; RB81: Reactive Blue 81; MR: Methyl Red; RR120: Reactive Red 120; RV5: Reactive Violet 5.

Acknowledgments

Not applicable. 


\section{Authors' contributions}

SA: Conceptualization, methodology, formal analysis, data curation, validation, visualization, writing-review and editing. RA-T: Methodology, data curation, writing-original draft. EK: Methodology, formal analysis, writing-original draft, preparation. MK: Investigation, visualization, funding acquisition, writingreview and editing. MK: Investigation, funding acquisition, writing-review and editing. TE: Software. ME-S: Investigation, writing-review and editing. JS: Conceptualization, funding acquisition, validation, visualization, writing-review and editing. All authors read and approved the final manuscript.

\section{Funding}

This work was supported by the National Key R\&D Program of China (2018YFE0107100), the National Natural Science Foundation of China (31772529), and the Project funded by the Priority of Academic Program Development of Jiangsu Higher Education Institutions (PAPD 4013000011). Prof. Michael Kornaros acknowledges that his work was supported by the project "INVALOR: Research Infrastructure for Waste Valorization and Sustainable Management" (MIS5002495) which is implemented under the Action "Reinforcement of the Research and Innovation Infrastructure", funded by the Operational Programme "Competitiveness, Entrepreneurship and Innovation" (NSRF 2014-2020) and co-financed by Greece and the European Union (European Regional Development Fund). This work was also supported by Taif University Researchers Supporting Project number (TURSP-2020/95), Taif University, Taif, Saudi Arabia.

\section{Availability of data and materials}

The datasets used and/or analyzed during the current study are available from the corresponding author on reasonable request.

\section{Ethics approval and consent to participate}

Not applicable.

\section{Consent for publication}

Not applicable.

\section{Competing interests}

The authors declare that they have no competing interests.

\section{Author details}

${ }^{1}$ Biofuels Institute, School of the Environment and Safety Engineering, Jiangsu University, Xuefu Rd. 301, Zhenjiang 212013, China. ${ }^{2}$ Botany Department, Faculty of Science, Tanta University, Tanta 31527, Egypt. ${ }^{3}$ Laboratory of Biochemical Engineering \& Environmental Technology (LBEET), Department of Chemical Engineering, University of Patras, 1 Karatheodori Str., University Campus, 26504 Patras, Greece. ${ }^{4}$ INVALOR: Research Infrastructure for Waste Valorization and Sustainable Management, University Campus, 26504 Patras, Greece. ${ }^{5}$ Department of Biology, College of Science, Taif University, P.O. Box 11099, Taif 21944, Saudi Arabia. ${ }^{6}$ Department of Plant Science, University of Manitoba, Winnipeg, MB R3T 2N2, Canada.

Received: 12 December 2020 Accepted: 16 February 2021 Published online: 08 March 2021

\section{References}

1. Martins F, Felgueiras C, Smitkova M, Caetano N. Analysis of fossil fuel energy consumption and environmental impacts in european countries. Energies. 2019;12:1-11.

2. York R, Bell SE. Energy transitions or additions?: Why a transition from fossil fuels requires more than the growth of renewable energy. Energy Res Soc Sci. 2019;51:40-3.

3. Mayer FD, Brondani M, Vasquez Carrillo MC, Hoffmann R, Silva Lora EE. Revisiting energy efficiency, renewability, and sustainability indicators in biofuels life cycle: analysis and standardization proposal. J Clean Prod. 2020;252:23.

4. Mat Aron NS, Khoo KS, Chew KW, Show PL, Chen WH, Nguyen THP. Sustainability of the four generations of biofuels-a review. Int J Energy Res. 2020;44:9266-82.

5. Kilbane JJ. Future applications of biotechnology to the energy industry. Front Microbiol. 2016;7:4-7.
6. Hasanbeigi A, Price L. A technical review of emerging technologies for energy and water efficiency and pollution reduction in the textile industry. J Clean Prod. 2015;95:30-44.

7. Sarkar S, Banerjee A, Halder U, Biswas R, Bandopadhyay R. Degradation of synthetic azo dyes of textile industry: a sustainable approach using microbial enzymes. Water Conserv Sci Eng. 2017;2:121-31.

8. Lade H, Kadam A, Paul D, Govindwar S. Biodegradation and detoxification of textile azo dyes by bacterial consortium under sequential microaerophilic/aerobic processes. EXCLI J Exp Clin Sci. 2015;14:158.

9. Sarayu K, Sandhya S. Current technologies for biological treatment of textile wastewater-a review. Appl Biochem Biotechnol. 2012;167:645-61.

10. Khan S, Anas M, Malik A. Mutagenicity and genotoxicity evaluation of textile industry wastewater using bacterial and plant bioassays. Toxicol Rep. 2019;6:193-201.

11. Ajaz M, Shakeel S, Rehman A. Microbial use for azo dye degradation-a strategy for dye bioremediation. Int Microbiol. 2020;23:149-59.

12. Imran M, Shaharoona B, Crowley DE, Khalid A, Hussain S, Arshad M. The stability of textile azo dyes in soil and their impact on microbial phospholipid fatty acid profiles. Ecotoxicol Environ Saf. 2015;120:163-8.

13. Al-Tohamy R, Kenawy E, Sun J, Ali SS. Performance of a newly isolated salt-tolerant yeast strain Sterigmatomyces halophilus SSA-1575 for azo dye decolorization and detoxification. Front Microbiol. 2020;11:1163.

14. Al-Tohamy R, Sun J, Fareed M, Kenawy E, Ali SS. Ecofriendly biodegradation of Reactive Black 5 by newly isolated Sterigmatomyces halophilus SSA1575, valued for textile azo dye wastewater processing and detoxification. Sci Rep. 2020;10:12370.

15. Ali SS, Al-Tohamy R, Koutra E, El-Naggar A, Kornaros M, Sun J. Valorizing lignin-like dyes and textile dyeing wastewater by a newly constructed lipid-producing and lignin modifying oleaginous yeast consortium valued for biodiesel and bioremediation. J Hazard Mater. 2021;403:123575.

16. Ali SS, Sun J, Koutra E, El-Zawawy N, Elsamahy T, El-Shetehy M. Construction of a novel cold-adapted oleaginous yeast consortium valued for textile azo dye wastewater processing and biorefinery. Fuel. 2021:285:119050.

17. Holkar CR, Jadhav AJ, Pinjari DV, Mahamuni NM, Pandit AB. A critical review on textile wastewater treatments: possible approaches. J Environ Manage. 2016;182:351-66.

18. Ali SS, Al-Tohamy R, Xie R, El-Sheekh M, Sun J. Construction of a new lipase- and xylanase-producing oleaginous yeast consortium capable of reactive azo dye degradation and detoxification. Bioresour Technol. 2020;313:123631.

19. Song L, Shao Y, Ning S, Tan L. Performance of a newly isolated salttolerant yeast strain Pichia occidentalis G1 for degrading and detoxifying azo dyes. Bioresour Technol. 2017;233:21-9.

20. Guo G, Tian F, Zhao Y, Tang M, Liu W, Liu C, Xue S, Kong W, Sun Y, Wang S. Aerobic decolorization and detoxification of Acid Scarlet GR by a newly isolated salt-tolerant yeast strain Galactomyces geotrichum GG. Int Biodeterior Biodegrad. 2019;2019(145):104818.

21. Yaguchi A, Franaszek N, O'Neill K, Lee S, Sitepu I, Boundy-Mills K, Blenner $\mathrm{M}$. Identification of oleaginous yeasts that metabolize aromatic compounds. J Ind Microbiol Biotechnol. 2020;47:801-13.

22. Singh G, Dwivedi SK. Decolorization and degradation of Direct Blue-1 (Azo dye) by newly isolated fungus Aspergillus terreus GS28, from sludge of carpet industry. EnvironTechnol Innov. 2020;18:100751.

23. Đurđić Kl, Ostafe R, Đelmaš AĐ, Popović N, Schillberg S, Fischer R, Prodanović R. Saturation mutagenesis to improve the degradation of azo dyes by versatile peroxidase and application in form of VP-coated yeast cell walls. Enzyme Microb Technol. 2020;136:109509.

24. Zhang H, Zhang X, Geng A. Expression of a novel manganese peroxidase from Cerrena unicolor BBP6 in Pichia pastoris and its application in dye decolorization and PAH degradation. Biochem Eng J. 2020;153:107402.

25. Lucas MS, Amaral C, Sampaio A, Peres JA, Dias AA. Biodegradation of the diazo dye Reactive Black 5 by a wild isolate of Candida oleophila. Enzyme Microb Technol. 2006:39:51-5.

26. Ramalho PA, Cardoso MH, Cavaco-Paulo A, Ramalho MT. Characterization of azo reduction activity in a novel ascomycete yeast strain. Appl Environ Microbiol. 2004;2004(70):2279-88. 
27. Yang $Q$, Yediler A, Yang M, Kettrup A. Decolourization of an azo dye, Reactive Black 5 and MnP production by yeast isolate: Debaryomyces polymorphus. Biochem Eng J. 2005;24:249-53.

28. Brune A. Symbiotic digestion of lignocellulose in termite guts. Nat Rev Microbiol. 2014;12(3):168-80.

29. Ali SS, Al-Tohamy R, Sun J, Wu J, Huang M. The role of gut symbionts from termites: a unique hidden player from yeasts. Acta Microbiologica Sinica. 2018;58(6):1-12.

30. Kuhnigk T, Borst EM, Ritter A, Kämpfer $P$, Graf A, Hertel H, König $H$. Degradation of lignin monomers by the hindgut flora of xylophagous termites. Syst Appl Microbiol. 1994;17(1):76-85.

31. Geib SM, Filley TR, Hatcher PG, Hoover K, Carlson JE, Jimenez-Gasco M, Nakagawa-Izumi A, Sleighter RL, Tien M. Lignin degradation in wood-feeding insects. PANS. 2008;105(35):12932-7.

32. Ni J, Tokuda G. Lignocellulose-degrading enzymes from termites and their symbiotic microbiota. Biotechnol Adv. 2013;31(6):838-50.

33. Sun JZ, Ding SY, Peterson DJ. Biological conversion of biomass for fuels and chemicals: Explorations from natural utilization systems. Cambridge: Royal Society of Chemistry; 2014

34. Janusz G, Pawlik A, Sulej J, Świderska-Burek U, Jarosz-Wilkołazka A, Paszczyński A. Lignin degradation: microorganisms, enzymes involved, genomes analysis and evolution. FEMS Microbiol Rev. 2017:41(6):941-62.

35. Schäfer A, Konrad R, Kuhnigk T, Kämpfer P, Hertel H, König H. Hemicellulose-degrading bacteria and yeasts from the termite gut. J Appl Bacteriol. 1996;80(5):471-8.

36. Máximo C, Pessoa Amorim MT, Costa-Ferreira M. Biotransformation of industrial reactive azo dyes by Geotrichum sp. CCMI 1019. Enzyme Microb Technol. 2003;32:145-51.

37. Baborová P, Möder M, Baldrian P, Cajthamlová K, Cajthaml T. Purification of a new manganese peroxidase of the white-rot fungus Irpex lacteus, and degradation of polycyclic aromatic hydrocarbons by the enzyme. Res Microbiol. 2006;157:248-53.

38. Cooksey KE, Guckert JB, Williams SA, Callis PR. Fluorometric determination of the neutral lipid content of microalgal cells using Nile Red. J Microbiol Methods. 1987;6:333-45.

39. Ali SS, Wu J, Xie R, Zhou F, Sun JZ, Huang M. Screening and characterizing of xylanolytic and xylose-fermenting yeasts isolated from the wood-feeding termite, Reticulitermes chinensis. PLOS ONE. 2017;12(7):e0181141.

40. Ali SS, Elsamahy T, Koutra E, Kornaros M, El-Sheekh M, Abdelkarim $\mathrm{E}$, Zhu D, Sun J. Degradation of conventional plastic wastes in the environment: A review on current status of knowledge and future perspectives of disposal. Sci Total Environ. 2021;144:719.

41. Urbina H, Schuster J, Blackwell M. The gut of Guatemalan passalid beetles: a habitat colonized by cellobiose- and xylose-fermenting yeasts. Fungal Ecol. 2013;6:339-55.

42. Sun JZ, Scharf ME. Exploring and integrating cellulolytic systems of insects to advance biofuel technology. Insect Sci. 2010;17:163-5.

43. Vaughan-Martini A, Kurtzman CP, Meyer SA, O'Neill EB. Two new species in the Pichia guilliermondii clade: Pichia caribbica sp. nov., the ascosporic state of Candida fermentati, and Candida carpophila comb. nov. FEMS yeast res. 2005:5(4-5):463-9.

44. Gong F, Sheng J, Chi Z, Li J. Inulinase production by a marine yeast Pichia guilliermondii and inulin hydrolysis by the crude inulinase. J ind microbiol biotechnol. 2007;34(3):179-85.

45. Zhao J, Mou Y, Shan T, Li Y, Zhou L. Antimicrobial metabolites from the endophytic fungus Pichia guilliermondii isolated from Paris polyphylla var. yunnanensis. Molecules. 2010;15(11):7961-70.

46. Wang GY, Chi Z, Song B, Wang ZP, Chi ZM. High level lipid production by a novel inulinase-producing yeast Pichia guilliermondii Pcla22. Bioresour technol. 2012;124:77-82.

47. Ramírez-Castrillón M, Jaramillo-Garcia VP, Rosa PD, Landell MF, Vu, D. Fabricio MF, Ayub MAZ, Robert V, Henriques JAP, Valente P. The oleaginous yeast Meyerozyma guilliermondii BI281A as a new potential biodiesel feedstock: selection and lipid production optimization. Front Microbiol. 2017;8:1776.

48. Ratledge C. Tan K-H. In: Verachtert HJ, De Mot R, editors. Yeast Biotechnology and Biocatalysis. New York: Marcel Dekker; 1990. p. 223-53.
49. Ramirez-Orozco M, Hernandez-Saavedra NY, Ochoa J-L. Debaryomyces hansenii growth in nonsterile seawater $\mathrm{ClO}_{2}$-peptone-containing medium. Can J Microbiol. 2001;47:676-9.

50. Breuer U, Harms H. Debaryomyces hansenii-an extremophilic yeast with biotechnological potential. Yeast. 2006;23:415-37.

51. Souza KS, Ramos CL, Schwan RF, Dias DR. Lipid production by yeasts grown on crude glycerol from biodiesel industry. Prep Biochem Biotechnol. 2017;47(4):357-63.

52. Sitepu IR, Jin M, Fernandez JE, da Costa SL, Balan V, Boundy-Mills KL. Identification of oleaginous yeast strains able to accumulate high intracellular lipids when cultivated in alkaline pretreated corn stover. Appl Microbiol Biotechnol. 2014;98(17):7645-57.

53. Rumin J, Bonnefond H, Saint-Jean B, Rouxel C, Sciandra A, Bernard O, Cadoret J-P, Bougaran G. The use of fluorescent Nile red and BODIPY for lipid measurement in microalgae. Biotechnol Biofuels. 2015;8:42.

54. Maza DD, Vinarta SC, Su Y, Guillamon JM, Aybar MJ. Growth and lipid production of Rhodotorula glutinis R4, in comparison to other oleaginous yeasts. J Biotechnol. 2020;2020(310):21-31.

55. Ayadi I, Belghith H, Gargouri A, Guerfali M. Screening of new oleaginous yeasts for single cell oil production, hydrolytic potential exploitation and agro-industrial by-products valorization. Process Saf Environ Prot. 2018;119:104-14

56. Ayadi I, Kamoun O, Trigui-Lahiani H, Hdiji A, Gargouri A, Belghith H, Guerfali M. Single cell oil production from a newly isolated Candida viswanathii Y-E4 and agro-industrial by-products valorization. J Ind Microbiol Biotechnol. 2016;43:901-14.

57. Vyas S, Chhabra M. Isolation, identification and characterization of Cystobasidium oligophagum JRC1: A cellulase and lipase producing oleaginous yeast. Bioresour Technol. 2017;223:250-8.

58. Patel A, Pravez M, Deeba F, Pruthi V, Singh RP, Pruthi PA. Boosting accumulation of neutral lipids in Rhodosporidium kratochvilovae HIMPA1 grown on hemp (Cannabis sativa Linn) seed aqueous extract as feedstock for biodiesel production. Bioresour Technol. 2014;165:214-22.

59. Liang YN, Tang TY, Umagiliyage AL, Siddaramu T, McCarroll M, Choudhary R. Utilization of sorghum bagasse hydrolysates for producing microbial lipids. Appl Energ. 2012;91:451-8.

60. Xie HB, Shen HW, Gong ZW, Wang Q, Zhao ZBK, Bai FW. Enzymatic hydrolysates of corn stover pretreated by a N-methylpyrrolidoneionic liquid solution for microbial lipid production. Green Chem. 2012;14:1202-10.

61. Patel A, Arora N, Sartaj K, Pruthi V, Pruthi PA. Sustainable biodiesel production from oleaginous yeasts utilizing hydrolysates of various non-edible lignocellulosic biomasses. Renew Sustain Energy Rev. 2016;62:836-55.

62. Slininger PJ, Dien BS, Kurtzman CP, Moser BR, Bakota EL, Thompson SR, O'Bryan PJ, Cotta MA, Balan V, Jin M, Dale BE. Comparative lipid production by oleaginous yeasts in hydrolyzates of lignocellulosic biomass and process strategy for high titers. Biotechnol Bioeng. 2016;113(8):1676-90.

63. lassonova DR, Hammond EG, Beattie SE. Oxidative stability of polyunsaturated triacylglycerols encapsulated in oleaginous yeast. J Am Oil Chem Soc. 2008:85:711-6.

64. Ratledge C. Fatty acid biosynthesis in microorganisms being used for Single Cell Oil production. Biochimie. 2004:86:807-15.

65. Evans CT, Ratledge C. A comparison of the oleaginous yeast, Candida curvata, grown on different carbon sources in continuous and batch culture. Lipids. 1983;18:623-9.

66. Ratledge C, Wynn J. The biochemistry and molecular biology of lipid accumulation in oleaginous microorganisms. In: Laskin Al, Bennett JW, Gadd GM, editors. Advances in applied microbiology. New York: Elsevier Science; 2002. p. 1-51.

67. Rossi M, Buzzini P, Cordisco L, Amaretti A, Sala M, Raimondi S, Ponzoni C, Pagnoni UM, Matteuzzi D. Growth, lipid accumulation, and fatty acid composition in obligate psychrophilic, facultative psychrophilic, and mesophilic yeasts. FEMS Microbiol Ecol. 2009;69:363-72.

68. Taskin M, Saghafian A, Aydogan MN, Arslan NP. Microbial lipid production by cold-adapted oleaginous yeast Yarrowia lipolytica B9 in nonsterile whey medium. Biofuels Bioprod Biorefining. 2015;9:595-605.

69. Ramos MJ, Fernandez CM, Casas A, Rodriguez L, Perez A. Influence of fatty acid composition of raw materials on biodiesel properties. Bioresour Technol. 2009;100:261-8. 
70. CEN. EN 14214 Automotive Fuels Diesel-Fatty Acid Methyl Esters (FAME)-Requirements and Test Methods. CEN Brussels, Belgium 2009.

71. Knothe G. Analyzing biodiesel: standards and other methods. J Am Oil Chem Soc. 2006;83:823-33.

72. Adalberto A, Neto K, Borin GP, Goldman GH, Ricardo A, Damásio DL, Castro JV. Insights into the plant polysaccharide degradation potential of the xylanolytic yeast Pseudozyma brasiliensis. FEMS yeast res. 2015;1:12.

73. Ribeiro BD, de Castro AM, Coelho MAZ, Freire DMG. Production and use of lipases in bioenergy: a review from the feedstocks to biodiesel production. Enzyme Res. 2011;1:16.

74. Abdelaziz OY, Brink DP, Gorwa-Grauslund MF. Biological valorization of low molecular weight lignin. Biotechnol Adv. 2016;34:1318-46.

75. Chong GG, Huang XJ, Di JH, Xu DZ, He YC, Pei YN, Tang YJ, Ma CL. Biodegradation of alkali lignin by a newly isolated Rhodococcus pyridinivorans CCZUB16. Bioprocess Biosyst Eng. 2018;41:501-10.

76. Li C, Chen C, Wu X, Tsang C-W, Mou J, Yan J, Liu Y, Lin C. Recent advancement in lignin biorefinery: With special focus on enzymatic degradation and valorization. Bioresour Technol. 2019;291:121898.

77. Wang Z, Li N, Pan X. Transformation of ammonia fiber expansion (AFEX) corn stover lignin into microbial lipids by Rhodococcus opacus. Fuel. 2019;240:119-25.

78. Almeida JRM, Modig T, Petersson A, Hähn-Hägerdal B, Lidén G, GorwaGrauslund MF. Mini-Review increased tolerance and conversion of inhibitors in lignocellulosic hydrolysates by Saccharomyces cerevisiae. J Chem Technol Biot. 2007;82:340-9.

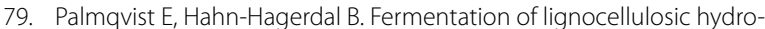
lysates II: Inhibitors and mechanisms of inhibition. Bioresour Technol. 2000:74:25-33.

80. Wang J, Gao Q, Zhang H, Bao J. Inhibitor degradation and lipid accumulation potentials of oleaginous yeast Trichosporon cutaneum using lignocellulose feedstock. Bioresour Technol. 2016;218:892-901.

81. Jin M, Slininger PJ, Dien BS, Waghmode S, Moser BR, Orjuela A, Sousa LDC, Balan V. Microbial lipid-based lignocellulosic biorefinery: feasibility and challenges. Trends Biotechnol. 2015;33:43-54.

82. Chen X, Li Z, Zhang X, Hu F, Ryu DDY, Bao J. Screening of oleaginous yeast strains tolerant to lignocellulose degradation compounds. Appl Biochem Biotechnol. 2009;159(3):591.

83. Poontawee R, Yongmanitchai W, Limtong S. Efficient oleaginous yeasts for lipid production from lignocellulosic sugars and effects of lignocellulose degradation compounds on growth and lipid production. Process Biochem. 2017:53:44-60.

84. Sagia S, Sharma A, Singh S, Chaturvedi S, Nain PK, Nain L. Single cell oil production by a novel yeast Trichosporon mycotoxinivorans for complete and ecofriendly valorization of paddy straw. Electron J Biotechnol. 2020;2020(44):60-8.

85. Hu C, Zhao X, Zhao J, Wu S, Zhao ZK. Effects of biomass hydrolysis by-products on oleaginous yeast Rhodosporidium toruloides. Bioresour Technol. 2009;100:4843-7.

86. Zhao X, Peng F, Du W, Liu C, Liu D. Effects of some inhibitors on the growth and lipid accumulation of oleaginous yeast Rhodosporidium toruloides and preparation of biodiesel by enzymatic transesterification of the lipid. Bioprocess Biosyst Eng. 2012;2012(35):993-1004.

87. Dowlath AJ, Karuppannan SK, Rajan P, Khalith SBM, Rajadesingu S, Arunachalam KD. Application of advanced technologies in managing wastes produced by leather industries-An approach toward zero waste technology. Concepts Adv Zero Waste Tools. 2021;143:79.

88. Fazal T, Mushtaq A, Rehman F, Khan A, Rashid N, Farooq W, Rehman M, Xu J. Bioremediation of textile wastewater and successive biodiesel production using microalgae. Renew Sust Energ Rev. 2018;82(3):3107-26.

89. Ngo A, Devanadera M, Dedeles G. Decolorization of selected synthetic textile dyes by yeasts from leaves and fruit peels. J Health Pollut. 2016;6(10):42-55.

90. Ruscasso F, Bezus B, Garmendia G, Vero S, Curutchet G, Cavello I, Cavalitto S. Debaryomyces hansenii F39A as biosorbent for textile dye removal. Revista Argentina de Microbiología. 2021. https://doi. org/10.1016/j.ram.2020.10.004.

91. Ali SS, Al-Tohamy R, Sun J, Wu J, Huizi L. Screening and construction of a novel microbial consortium SSA-6 enriched from the gut symbionts of wood-feeding termite, Coptotermes formosanus and its biomass-based biorefineries. Fuel. 2019;236:1128-45.
92. Sharma DK, Saini HS, Singh M, Chimni SS, Chadha BS. Isolation and characterization of microorganisms capable of decolorizing various triphenylmethane dyes. J Basic Microbiol. 2004;44:59-65.

93. Liao CS, Hung $\mathrm{CH}$, Chao SL. Decolorization of azo dye reactive black $B$ by Bacillus cereus strain HJ-1. Chemosp. 2012;90:2109-14.

94. Pearce Cl, Lloyd JR, Guthriea JT. The removal of colour from textile wastewater using whole bacterial cells: a review. Dyes Pigm. 2003;58:179-96.

95. Kumari L, Verma AK, Tiwary D, Giri DD, Nath G, Mishra PK. Biodegradation of Navy N5RL1 carpet dye by Staphylococcus saprophyticus strain BHUSS X3. Biotech. 2015;5:775-82.

96. Ghodake G, Jadhav U, Tamboli D, Kagalkar A, Govindwar S. Decolorization of textile dyes and degradation of mono-azo dye amaranth by Acinetobacter calcoaceticus NCIM 2890. Indian J Microbiol. 2011;51:501-8.

97. Kalyani DC, Telke AA, Dhanve RS, Jadhav JP. Ecofriendly Biodegradation and detoxification of Reactive Red 2 textile dye by newly isolated Pseudomonas sp SUK1. J Hazard Mater. 2008;163:735-42.

98. Saratale RG, Saratale GD, Chang JS, Govindwar SP. Decolorization and biodegradation of textile dye Navy blue HER by Trichosporon beigelii NCIM-3326. J Hazard Mater. 2009;166:1421-8.

99. Stolz A. Basic and applied aspects in the microbial degradation of azo dyes. Appl Microbiol Biotechnol. 2001;56:69-80.

100. Yang X, Wang J, Zhao X, Wang Q, Xue R. Increasing manganese peroxidase production and biodecolorization of triphenylmethane dyes by novel fungal consortium. Bioresour Technol. 2011;102(22):10535-41.

101. Ali SS, Mustafa AM, Kornaros M, Sun J, Khalil M, El-Shetehy M. Biodegradation of creosote-treated wood by two novel constructed microbial consortia for the enhancement of methane production. Bioresour Technol. 2021;323:124544.

102. Prabhakar Y, Gupta A, Kaushik A. Enhanced decolorization of reactive violet dye 1 by halo-alkaliphilic Nesterenkonia strain: Process optimization, short acclimatization and reusability analysis in batch cycles. Process Saf Environ Prot. 2019;131:116-26

103. Xu S, Qian W, Zhang D, Zhao X, Zhang X, Li C, Bowen CR, Yang Y. A coupled photo-piezo-catalytic effect in a BST-PDMS porous foam for enhanced dye wastewater degradation. Nano Energy. 2020;105:305.

104. Paszcynski A, Huynh VB, Crawford RL. Enzymatic activities of an extracellular manganese dependent peroxidase from Phanerochaete chrysosporium. FEMS Microbiol Lett. 1985;29:37-41.

105. Rodriguez CS, Sanroman MA, Gubitz GM. Influence of redox mediators and metal ions on synthetic acid dye decolorization by crude laccase from Trametes hirsute. Chemosph. 2005;2005(58):417-22.

106. Levin L, Melignani E, Ramos AM. Effect of nitrogen sources and vitamins on ligninolytic enzyme production by some white-rot fungi. Dye decolorization by selected culture filtrates. Bioresour Technol. 2010;101:4554-63.

107. Yang Q, Li C, Li H, Li Y, Yu N. Degradation of synthetic reactive azo dyes and treatment of textile wastewater by a fungi consortium reactor. Biochem Eng J. 2009;43(3):225-30.

108. Khan R, Bhawana P, Fulekar MH. Microbial decolorization and degradation of synthetic dyes: a review. Rev Environ Sci Biotechnol. 2013;12:75-97.

109. Gonzalez-Gutierrez LV, Gonzalez-Alatorre G, Escamilla-Silva EM. Proposed pathways for the reduction of a reactive azo dye in an anaerobic fixed bed reactor. World J Microbiol Biotechnol. 2009;25:415-26.

110. Gingell R, Walker R. Mechanisms of azo reduction by Streptococcus faecalis II, the role of soluble flavins. Xenobiotica. 1971;1:231-9.

111. Chang JS, Kuo TS, Chao YP, Ho JY, Lin PJ. Azo dye decolorization with a mutant Escherichia coli strain. Biotechnol Lett. 2000;22:807-12.

112. Jadhav JP, Kalyani DC, Telke AA, Phugare SS, Govindwar SP. Evaluation of the efficacy of a bacterial consortium for the removal of color, reduction of heavy metals, and toxicity from textile dye effluent. Bioresour Technol. 2010;101:165-73.

113. Saratale RG, Saratale GD, Chang JS, Govindwar SP. Bacterial decolorization and degradation of azo dyes: A review. J Taiwan Inst Chem Eng. 2011:42(1):138-57.

114. Jadhav UU, Dawkar W, Ghodake GS, Govindwar SP. Biodegradation of Direct Red 5B, a Textile Dye by Newly Isolated Comamonas sp. UVS J Hazard Mater. 2008;158:507.

115. Saratale RG, Saratale GD, Kalyani DC, Chang JS, Govindwar SP. Enhanced Decolorization and Biodegradation of Textile Azo Dye Scarlet R 
by Using Developed Microbial Consortium-GR. Bioresour Technol. 2009;100:2493.

116. Tamboli D, Gomare S, Jadhav S, Jadhav U, Govindwar S. Consortial degradation of Orange $3 R$, mixture of dyes and textile effluent and production of polyhydroxyalkanoates from biomass obtained after degradation. Int Biodeterior Biodegrad. 2010;64:755-63.

117. Knothe G, Steidley RK. Kinematic viscosity of biodiesel fuel components and related compounds Influence of compound structure and comparison to petrodiesel fuel components. Fuel. 2005;84:1059.

118. Sani S, Kaisan MU, Kulla DM, Obi Al, Jibrin A, Ashok B. Determination of physico chemical properties of biodiesel from Citrullus lanatus seeds oil and diesel blends. Ind Crops Prod. 2018;122:702.

119. Renugadevi K, Valli Nachiyar C, Padmavathy H, Anjali DP. Coupling dye degradation and biodiesel production by Geitlerinema sp TRV27. Indian J Biochem Biophys. 2019;56:309-15.

120. Selvan BK, Revathi M, Piriya PS, Vasan PT, Prabhu DI, Vennison SJ. Biodiesel production from marine cyanobacteria cultured in plate and tubular photobioreactors. Indian J Exp Biol. 2013;51:262.

121. Moser BR. Influence of blending canola, palm, soybean, and sunflower oil methyl esters on fuel properties of biodiesel. Energy Fuels. 2008;22:4301.

122. Sivaramakrishnan K, Ravikumar P. Determination of cetane number of biodiesel and it's influence on physical properties. ARPN J Eng Appl Sci. 2012;7:205.

123. Sandhya S, Sarayu K, Uma B, Swaminathan K. Decolorizing kinetics of a recombinant escherichia coli SS125 strain harboring azoreductase gene from Bacillus latrosporus RRK1. Bioresour Technol. 2008;99(7):2187-91.

124. Mani P, Keshavarz T, Chandra TS, Kyazze G. Decolourization of acid orange 7 in a microbial fuel cell with a laccase-based biocathode: Influence of mitigating ph changes in the cathode chamber. Enzyme Microb Technol. 2017;96:170-6.

125. Gong J, Wang F, Ren Y, Li Z, Zhang J, Li Q. Preparation of biomass pigments and dyeing based on bioconversion. J Cleaner Product. 2018;182:301-12.

126. Pandey $A$, Singh $P$, lyengar $L$. Bacterial decolorization and degradation of azo dyes. Int J Biodeterior Biodegrad. 2007;59:73-84.

127. Gao D, Du L, Yang J, Wu WM, Liang H. A critical review of the application of white rot fungus to environmental pollution control. Crit Rev Biotechnol. 2010;30:70-7.

128. Lan J, Huang X, Hu M, Li Y, Qu Y, Gao P, Wu D. High efficient degradation of dyes with lignin peroxidase coupled with glucose oxidase. J Biotechnol. 2006;123:483-90.

129. Zhang C, Shen H, Zhang X, Yu X, Wang H, Xiao S, Wang J, Zhao Z. Combined mutagenesis of Rhodosporidium toruloides for improved production of carotenoids and lipids. Biotechnol Lett. 2016;38(10):1733-8.
130. Zhuo R, Zhang J, Yu H, Ma F, Zhang X. The roles of Pleurotus ostreatus HAUCC 162 laccase isoenzymes in decolorization of synthetic dyes and the transformation pathways. Chemosphere. 2019;234:733-45.

131. Chivukula M, Renganathan V. Phenolic azo dye oxidation by laccase from Pyricularia oryzae. Appl Environ Microbiol. 1995;61:4374-7.

132. Rivera-Hoyos CM, Morales-Alvarez ED, Poutou-Pinales RA, Pedroza-Rodriguez AM, Rodriguez-Vazquez R, Delgado-Boada JM. Fungal laccases. Fungal Biol Rev. 2013;27:67-82.

133. Suh S-O, Blackwell M. Four new yeasts in the Candida mesenterica clade associated with basidiocarpfeeding beetles. Mycologia. 2005;97:170-80.

134. Suutari M, Priha P, Laakso S. Temperature shifts in regulation of lipids accumulated by Lipomyces starkeyi. J Am Oil Chem Soc. 1993:70(9):891-4.

135. Floch J. A simple method for the isolation and purification of total lipids from animal tissues. J Biol Chem. 1957;226(1):497-509.

136. Miller GL. Use of dinitrosalicyclic reagent for determination of reducing sugar. Anal Chem. 1959;31:426-8.

137. Gomez-Alonso S, Hermosin-Gutierrez I, Garcia-Romero E. Simultaneous HPLC analysis of biogenic amines, amino acids, and ammonium ion as aminoenone derivatives in wine and beer samples. J Agric Food Chem. 2007;55:608-13.

138. Alvarez AF, Alvarez HM, Kalscheuer R, Waltermann M, Steinbuchel A. Cloning and characterization of a gene involved in triacylglycerol biosynthesis and identification of additional homologous genes in the oleaginous bacterium Rhodococcus opacus PD630. Microbiol. 2008;154:2327-35.

139. Srinu A, Vijaya LD, Murali S, Prasad DVR. Decolorization of anthraquinone dyes by Aspergillus strains and also optimization of lignolytic enzymes. Int J Rec Sci Res. 2017;8(7):18547-53.

140. Adnan LA, Yusoff ARM, Hadibarata T, Khudhair AB. Biodegradation of bis-azo dye reactive black 5 by white-rot fungus Trametes gibbosa sp. WRF 3 and its metabolite characterization. Water Air Soil Pollut. 2014;225:10.

141. Velikova V, Yordanov I, Edreva A. Oxidative stress and some anti oxidant system in acid rain treated bean plants: protective role of exogenous polyamines. Plant Sci. 2000;151(1):59-66.

142. Morais CG, Lara CA, Marques S, Fonseca C, Lachance M-A, Rosa CA. Sugiyamaella xylanicola sp. nov., a xylan-degrading yeast species isolated from rotting wood. Int J Syst Evol Microbiol. 2013;63:2356-60.

\section{Publisher's Note}

Springer Nature remains neutral with regard to jurisdictional claims in published maps and institutional affiliations.
Ready to submit your research? Choose BMC and benefit from:

- fast, convenient online submission

- thorough peer review by experienced researchers in your field

- rapid publication on acceptance

- support for research data, including large and complex data types

- gold Open Access which fosters wider collaboration and increased citations

- maximum visibility for your research: over $100 \mathrm{M}$ website views per year

At BMC, research is always in progress.

Learn more biomedcentral.com/submissions 